\title{
Using Expectations to Test Asset Pricing Models
}

\author{
Alon Brav, Reuven Lehavy, and Roni Michaely*
}

\begin{abstract}
Asset pricing models generate predictions relating assets' expected rates of return and their risk attributes. Most tests of these models have employed realized rates of return as a proxy for expected return. We use analysts' expected rates of return to examine the relation between these expectations and firm attributes. By assuming that analysts' expectations are unbiased estimates of market-wide expected rates of return, we can circumvent the use of realized rates of return and provide evidence on the predictions emanating from traditional asset pricing models. We find a positive, robust relation between expected return and market beta and a negative relation between expected return and firm size, consistent with the notion that these are risk factors. We do not find that high book-to-market firms are expected to earn higher returns than low book-to-market firms, inconsistent with the notion that book-to-market is a risk factor.
\end{abstract}

Asset pricing models seek to establish the determinants of financial assets' expected rates of return. Classic asset pricing models, such as Sharpe (1964), Lintner (1965), and Black (1972), predict that an asset's expected return should be positively related to its systematic market risk. Based on Merton's (1973) ICAPM, Fama and French $(1992,1993)$ argue that their findings of higher returns for high book-to-market stocks and low capitalization stocks reflect compensation for risk. That is, those stocks are expected to earn higher rates of return because they are riskier.

Although asset pricing models aim at explaining cross-sectional variation in expected return, researchers have been forced to use realized return as a proxy for expected return in tests of these models. The use of realized returns implies that such tests are conditioned on the joint hypothesis of rational expectations, in the sense that the average realization is a good proxy for expectation and that the null asset pricing model describes the relation between expectations and firm attributes. However, realized return may not be a perfect proxy for expected return. First, noise in realized returns is likely to be large (Blume and Friend, 1973 and Sharpe, 1978). Second, realized returns may be poor estimates of expected returns if information surprises do not cancel out over the period of study (Froot and Frankel, 1989 and Elton, 1999). Third, realized returns may also be noisy and biased estimates of expected returns due to complex learning effects. ${ }^{1}$

${ }^{1}$ See Blume and Easley (1982, 1998) and Bray and Kreps (1987). More recently, Lewellen and Shanken (2002) and Brav and Heaton (2002) argue that rational learning can generate price paths that, ex post, yield "value-" and "momentum-" type effects in stock returns.

We thank Yakov Amihud, Malcolm Baker, Ravi Bansal, Brad Barber, Larry Blume, Kobi Boudoukh, Markus Brunnermeier, Peter Demerjian, Magnus Dahlquist, Wayne Ferson, John Graham, Campbell Harvey, J.B. Heaton, Matt Richardson, Jay Shanken, Hersh Shefrin, Andrei Shleifer, Meir Statman, Avanidhar Subrahmanyam, seminar participants at Cornell University, Columbia University, Duke University, Emory University, Harvard Business School, the Interdisciplinary Center Herzlyia, Israel, Michigan State University, MIT, New York University, Rice University, TelAviv University, Texas Christian University, Tulane University, Tuck School of Business at Dartmouth, The Wharton School, University of British Columbia, University of California Berkeley, University of Chicago, University of Colorado at Boulder, University of Florida, University of Haifa, University of Rochester, University of Washington, Seattle, University of Wisconsin, Madison, Vanderbilt University, Washington University in St. Louis, Yale University, the 2003 Western Finance Association meetings in Los Cabos, Mexico, the 2003 Utah Winter Finance Conference, and John Nugent from Value Line Institutional Services for their comments. We owe special thanks to Michael Roberts for his suggestions.

"Alon Brav is an Associate Professor of Finance at Duke University in Durham, NC. Reuven Lehavy is an Assistant Professor of Accounting at the University of Michigan in Ann Arbor, Michigan. Roni Michaely is the Rudd Family Professor of Management at Cornell University in Ithaca, NY.

Financial Management • Autumn 2005 pages 5 - 37 
We complement previous research by using analysts' ex ante measures of expected returns and test the relation between these expectations and several factors that explain crosssectional variation in ex post realized returns. These factors include beta, book-to-market, market capitalization, and price momentum. For example, the prediction emanating from a rational asset-pricing model such as the CAPM is that beta is priced by the market. Therefore, the expected return on high beta stocks should be higher than the expected return on low beta stocks. Likewise, following Fama and French (1993), if firms with larger loadings on a book-to-market factor are riskier than firms with smaller loadings, then the former firms should earn higher expected returns than the latter. We provide evidence on these predictions and the importance of these factors using ex ante measures of expected returns.

It is important to recognize that using expected rates of return in lieu of realized returns raises a subtle issue related to the distinction between the predictions generated by the null asset pricing model and the auxiliary assumptions that are needed to "take the model to the data." Our use of analyst expectations embodies the assumption that these expectations reflect market-wide expectations. Similarly, rational expectations is an auxiliary assumption that is internally consistent with the other model assumptions and enables the use of realized returns in asset pricing tests. Those who believe that quick convergence to a rational expectations equilibrium is an unreasonable assumption due to complex learning dynamics (e.g., Blume and Easley, 1998), may view realized returns as a biased and noisy proxy for investors' expectations (Sharpe, 1978, Elton, 1999, and Lewellen and Shanken, 2002). Using expectations directly does not require the assumption that expectations are rational, constant over time, or that there is no learning. Indeed, as Sharpe (1978) has pointed out:

"All the econometric sophistication in the world will not completely solve the basic problem associated with the use of ex post data to test theories dealing with ex ante prediction, however. The Capital Asset Pricing Model deals with predictions concerning a future period [...]. It does not assume that the predictions or the implied relationships among them are stable over time. Nor does it assume that actual results will accord with such predictions, either period-by-period or, in any simple sense, 'on average'.” (p. 920)

Our approach is subject to the criticism that the set of expectations we use is not a good proxy for market's expectations and, therefore, does not allow for a test of an asset pricing model. Although market expectations are unobservable, there are several reasons to believe that our measures of expected return represent a significant portion of the market's expectations. First, the Value Line and First Call estimates that we use impact market prices (Affleck-Graves and Mendenhall, 1992 and Womack, 1996). Second, researchers and practitioners have been using analysts' earnings and growth forecasts as a proxy for the market's estimates of these variables. Third, subscribers to both databases (which include individual investors, brokerage and asset management firms, and corporations) have been paying for these services (directly or indirectly) and it is likely that they would adopt these expectations (Ang and Peterson, 1985). Fourth, coverage is wide for both databases. Finally, Value Line expectations are unlikely to suffer from incentives-related biases. Therefore, we use these expectations in our main tests.

Since conclusive evidence on the suitability of either of these two auxiliary assumptions (rational expectations compared to our ex ante proxy reflecting market-wide expectations) is debatable, by replacing one auxiliary assumption with another we believe that our tests can only enhance our knowledge on the viability of the null asset pricing models.

We draw our expected return data primarily from Value Line, an independent research 
provider that covers approximately 3,800 stocks. We examine the period 1975-2001. Our sample comprises $92 \%$ of the NYSE, AMEX, and Nasdaq in terms of market value. To ensure that our results are not unique only to Value Line expectations, we augment our analysis by using First Call as an additional source of analysts' expectations to create a large sample of analysts' expected returns. These expected returns are obtained from sell-side analysts for as many as 7,000 firms during the period 1997 through 2001.

Our first finding concerns one of the most important questions in the asset pricing literature: Is beta priced? Using realized returns as a proxy for expected returns, the evidence is mixed. Early tests, such as Black, Jensen, and Scholes (1972), and Fama and MacBeth (1973) find that firms' betas are positively related to their realized returns. Using later data and monthly return intervals, Fama and French $(1992,1993)$ and others do not find a significant relation. However, when annual return intervals are used (Kothari, Shanken, and Sloan, 1995) find that beta is significantly related to average realized returns.

Unlike many of the tests that use ex post return data, we find that beta risk is positively associated with expected returns. This finding is consistent with traditional asset pricing models. The price of beta risk is statistically significant and within a reasonable economic range. The results indicate a market risk premium of around seven percent per year.

With respect to market capitalization, we find that smaller capitalization stocks are expected to earn higher returns than large capitalization stocks. This result is consistent with the findings in other studies that use realized returns. The findings of higher expected return and higher average realized return on small capitalization stocks suggests that size is a risk factor, over and above market beta.

Using Value Line expectations, we do not find evidence that high book-to-market stocks have higher expected returns than low book-to-market stocks. When we use the sell-side analysts expected returns from First Call, we find that the coefficient on book-to-market is negative and significant. Regardless of the source of expectations, these results are not consistent with the notion that the market perceives high book-to-market stocks as riskier and that therefore they command higher expected returns. ${ }^{2}$

We also examine whether the momentum factor (or prior return characteristic) is priced. We find that generally, it is priced, but that the sign is negative. This finding suggests that investors expect stocks with high past returns to have lower returns in the future than will stocks with low or negative returns. In other words, investors do not consider stocks that have recently performed well ("winner stocks") as riskier and thus require higher expected returns than recent "loser" stocks.

Although most asset pricing tests utilize realized rates of return as a proxy for expected return, there are a few studies that employ other proxies. Ang and Peterson (1985) were the first to investigate the relation between expected return and firm characteristics, using yearend expected return data constructed from Value Line during 1973-1983. Their study examines the relation between expected returns and dividend yields. They also report a negative relation between expected return and firm size and a positive relation between expected return and beta. Shefrin and Statman (2002) use an ordinal ranking of recommendations as their proxy for expected returns and relate them to firm characteristics such as book-tomarket and market capitalization. They find that stocks with buy recommendations are more likely to be low book-to-market stocks. They interpret this finding as an indication of higher expected return for those types of stocks, which is consistent with our findings. They also report that large stocks are more likely to receive buy recommendations than small stocks. In

${ }^{2}$ This result is consistent with the survey evidence in Bloomfield and Michaely (2004) regarding analysts' risk perceptions. 
contrast, we find that, holding other factors constant, small stocks exhibit higher expected return. Using Value Line forecasts of dividends and target prices, Botosan and Plumlee (2005) obtain estimates of firm cost of capital and ask whether these estimates are correlated with firm characteristics. They also find a positive relation between market beta and cost of equity. Contrary to the findings in Ang and Peterson (1985) and this article, Botosan and Plumlee generally find no association between market capitalization and Value Line estimates of the cost of equity. ${ }^{3}$

A related literature uses sell-side analysts' earnings forecasts within a DCF model, like the Gordon growth model to extract the firm's implied cost of capital (e.g., Friend, Westerfield, and Granito, 1978; Gebhardt, Lee, Swaminathan, 2001; Claus and Thomas, 2001; and Harris, Marston, Mishra, and O'Brien, 2003). These papers are important because they reveal information on the patterns in implied expectations. However, in contrast to the current paper, and as Sharpe (1978) points out, this method relies on a specific discounted cashflow formulation and requires strong assumptions about the forecast horizon, growth rates, and the methods by which analysts estimate firms' terminal values. By using analysts' expected returns directly, our work differs from previous studies because we are able to avoid making such critical auxiliary assumptions.

The article is organized as follows. We present the data and variable definitions in Section I. Section II presents the relations between expected return and factor loadings or firm characteristics. In Section III we introduce an additional proxy for expected returns and examine how these expectations are related to stocks' attributes. In Section IV we conduct various robustness checks. Section V concludes.

\section{Data and Variable Descriptions}

In this section, we describe the Value Line target price database as well as the computation of our proxy for the ex ante expected return.

\section{A. Data Description}

We construct estimates of expected returns using analysts' target prices. We obtain most of our data on target prices from Value Line (hereafter, VL). VL publishes weekly research reports for individual companies. It analyzes each company on a quarterly cycle such that a typical firm receives four reports per year.

The target price information provided by the VL service has several distinguishing features. First, VL is an independent research service with no affiliation to investment banking activity. Hence, analysts' optimism bias (Rajan and Servaes, 1997) or conflict of interest bias (Michaely and Womack, 1999) is less likely to affect its expected return estimates. ${ }^{4}$ In fact, given the structure of VL recommendations, there is no reason to believe that they have either positive

${ }^{3}$ Expectations have been utilized in tests of several additional assets pricing models. For example, Froot (1989) uses interest-rate expectations from a survey of financial market participants to test the expectations hypothesis. Froot and Frankel (1989) employ exchange rate expectations in studying the forward discount bias. Examining the impact of information surprises on bond pricing, Elton (1999) uses information from a survey by the Money Market Survey, and Welch (2000) uses a survey of 226 academics to estimate the expected market risk premium. ${ }^{4}$ In the lawsuit New York State brought against five executives in connection with IPO spinning by Salomon Smith Barney, one of the Salomon brokers is quoted as saying, "Perhaps, as brokers, we should subscribe to Morningstar or Value Line where research opinions are not based on influence by underwriting fees or the interest of the firm but on the best interest." (Filed at the Supreme Court of the State of New York, by State of New York and Elliot Spitzer, September $30^{\text {th }} 2002$.) 
or negative bias. VL has as many reports with very positive recommendations (timeliness rank equals one) as reports with very negative recommendations (timeliness rank equals five). Second, VL's historical file contains a long time series of historical expected returns which we collect for 1975 through 2001. Third, VL estimates cover approximately $90 \%$ of US traded firms in terms of their market value. These features (independence, long time series of returns, and wide cross-sectional coverage) distinguish the VL estimates from other available estimates of expected returns. While it is likely that VL estimates of expected return are correlated with the market's expectation, it is possible that they do not precisely represent those expectations. Following Froot and Frankel (1989) we assume that VL expectations are equal to the market expectations plus a random measurement error.

Although there is a clear parallel between our setting and the standard asset pricing tests that use realized returns as a proxy for expected returns, there are several differences that impact the statistical inferences below. First, the standard error of the measure we use in this paper is smaller than the one produced by using realized returns as a proxy for expected returns. Second, the problem of overlapping observations is not as severe. For example, if we were to use realized returns and a one-year investment horizon revised every month, the number of independent observations would be limited, since the month t observation would have an 11-month overlap with the observation in month $t+1$. This is not the case with expected returns since expectations are reformed at time $t$ and $t+1$ and thus they are independent of future realizations. However, expectations are serially correlated and we account for this time-series structure in our inferences. Third, even when we abstract from these advantages, the use of expectations provides an independent test of those models. This test is not subject to the data mining problem described in Black (1986). ${ }^{5}$

\section{The Value Line Database}

Table I, Panel A, provides descriptive statistics on the Value Line database for the period 1975 through $2001 .^{6}$ We start with approximately 5,600 price target reports in 1975, and reach about 5,800 reports in 2001, with an annual average of 5,361 price targets. The target price database includes reports for 3,823 distinct firms. In our analysis we allow only firms with common shares (CRSP share codes 10 and 11).

Panels B through D of Table I describe the size, book-to-market, and prior price momentum characteristics of our sample firms relative to the universe of firms available on CRSP. We compute the size in month $t$ as the market capitalization, expressed in millions of dollars, as of the end of the prior month. We compute book-to-market as the ratio of annual common shareholders' equity (Compustat item \#60) to market capitalization as of the end of the fiscal year. We apply this ratio to the 12-month period beginning six months subsequent to the end of the fiscal year. Prior price momentum for month $t$ is the buy-and-hold return for the 11month period ending one month prior to month $\mathrm{t}$. We present statistics for each characteristic within decile portfolios. We base the size deciles on NYSE capitalization cutoffs, and the book-to-market and momentum cutoffs on the universe of available firms on CRSP excluding those with non-common shares. For each decile, we report the mean of the monthly averages of the respective characteristic.

\footnotetext{
${ }^{5}$ Evidence from earlier sample periods (Davis, Fama, and French, 2000) as well as international evidence (Rouwenhorst, 1998) suggests that these effects are not likely to be an outcome of data snooping. Indeed, the current debate is mainly on why these factors are priced and not whether they are priced.

${ }^{6}$ We purchased our data for the period 1987-2001 directly from Value Line Institutional Services. We handcollected individual reports for the period 1975-1986 and for several weeks in which we found missing data in the period 1987-2001.
} 
Table I. Description of Value Line Target Price Database, 1975-2001

This table reports statistics on the Value Line target price database. Panel A presents, by year, the number of observations, number of firms, and the percent market capitalization of the sample firms relative to the universe of firms listed on the NYSE, AMEX, and Nasdaq. The last column in panel A presents statistics for the 27-year sample period. Panels B-D describe the size, book-to-market, and prior price momentum characteristics of our sample firms relative to the universe of firms available on CRSP. We compute the size in month $t$ as the market capitalization as of the end of the prior month (expressed in millions of dollars). We compute book-to-market as the ratio of annual common shareholders equity (Compustat item \#60) to market capitalization as of the end of the fiscal year. We apply this ratio to the 12-month period beginning six months after the end of the fiscal year. Prior price momentum for month $t$ is the buyand-hold return for the 11-month period ending one month prior to month $\mathrm{t}$. We present statistics for each characteristic within decile portfolios. We base the size deciles on NYSE capitalization cutoffs, and book-to-market and momentum cutoffs on the universe of available firms, excluding those with noncommon shares (CRSP share codes different from 10 or 11). For each decile, we report the mean of the monthly averages of the respective characteristic.

\begin{tabular}{|c|c|c|c|}
\hline \multicolumn{4}{|c|}{ Panel A. Value Line Target Price Database } \\
\hline Year & Number of Target Prices & Number of Firms & $\%$ of Market Capitalization \\
\hline 1975 & 5,579 & 1,526 & $95 \%$ \\
\hline 1976 & 5,059 & 1,554 & $95 \%$ \\
\hline 1977 & 5,862 & 1,604 & $95 \%$ \\
\hline 1978 & 5,871 & 1,600 & $95 \%$ \\
\hline 1979 & 5,968 & 1,612 & $95 \%$ \\
\hline 1980 & 5,805 & 1,634 & $95 \%$ \\
\hline 1981 & 5,985 & 1,615 & $94 \%$ \\
\hline 1982 & 6,017 & 1,609 & $94 \%$ \\
\hline 1983 & 5,062 & 1,543 & $93 \%$ \\
\hline 1984 & 5,616 & 1,555 & $93 \%$ \\
\hline 1985 & 4,993 & 1,510 & $93 \%$ \\
\hline 1986 & 5,195 & 1,452 & $93 \%$ \\
\hline 1987 & 5,291 & 1,487 & $93 \%$ \\
\hline 1988 & 5,395 & 1,478 & $93 \%$ \\
\hline 1989 & 5,245 & 1,421 & $93 \%$ \\
\hline 1990 & 5,196 & 1,395 & $94 \%$ \\
\hline 1991 & 5,202 & 1,371 & $94 \%$ \\
\hline 1992 & 5,184 & 1,370 & $93 \%$ \\
\hline 1993 & 5,292 & 1,368 & $92 \%$ \\
\hline 1994 & 5,184 & 1,392 & $91 \%$ \\
\hline 1995 & 5,174 & 1,387 & $90 \%$ \\
\hline 1996 & 5,067 & 1,365 & $90 \%$ \\
\hline 1997 & 5,100 & 1,424 & $90 \%$ \\
\hline 1998 & 5,100 & 1,436 & $91 \%$ \\
\hline 1999 & 5,328 & 1,451 & $92 \%$ \\
\hline 2000 & 5,645 & 1,569 & $91 \%$ \\
\hline 2001 & 5,771 & 1,575 & $92 \%$ \\
\hline $1975-2001$ & 146,186 & 3,823 & $92 \%$ \\
\hline
\end{tabular}


Table I. Description of Value Line Target Price Database, 1975-2001 (Continued)

\begin{tabular}{|c|c|c|c|c|c|c|c|c|c|c|c|}
\hline \multicolumn{12}{|c|}{ Panel B. Size Characteristics } \\
\hline & \multicolumn{11}{|c|}{$\begin{array}{ll} & \text { Size }\end{array}$} \\
\hline & Small & 2 & 3 & 4 & 5 & 6 & 7 & 8 & 9 & Large & Overall \\
\hline \multicolumn{12}{|l|}{ Universe: } \\
\hline Average Market Cap & 23 & 104 & 212 & 360 & 564 & 867 & 1,359 & 2,264 & 4,199 & 18,317 & 688 \\
\hline Percentage of Firms & $54.4 \%$ & $14.6 \%$ & $8.0 \%$ & $5.6 \%$ & $4.2 \%$ & $3.4 \%$ & $3.0 \%$ & $2.6 \%$ & $2.2 \%$ & $2.1 \%$ & $100.0 \%$ \\
\hline \multicolumn{12}{|l|}{ Value Line Population: } \\
\hline Average Market Cap & 36 & 110 & 216 & 362 & 567 & 870 & 1,362 & 2,267 & 4,203 & 18,320 & 2,025 \\
\hline Percentage of Firms & $14.9 \%$ & $16.1 \%$ & $13.2 \%$ & $11.2 \%$ & $9.5 \%$ & $8.5 \%$ & $7.8 \%$ & $7.1 \%$ & $6.1 \%$ & $5.6 \%$ & $100.0 \%$ \\
\hline \multicolumn{12}{|c|}{ Panel C. Book-to-Market Characteristics } \\
\hline & \multicolumn{11}{|c|}{ Book-to-Market } \\
\hline & Low & 2 & 3 & 4 & 5 & 6 & 7 & 8 & 9 & High & Overall \\
\hline \multicolumn{12}{|l|}{ Universe: } \\
\hline Average Book-to-Market & 0.18 & 0.34 & 0.48 & 0.61 & 0.74 & 0.87 & 1.03 & 1.22 & 1.53 & 2.44 & 0.94 \\
\hline \multicolumn{12}{|l|}{ Value Line Population: } \\
\hline Average Book-to-Market & 0.19 & 0.34 & 0.48 & 0.61 & 0.74 & 0.87 & 1.02 & 1.22 & 1.53 & 2.34 & 0.83 \\
\hline Percentage of Firms & $8.9 \%$ & $11.4 \%$ & $11.9 \%$ & $11.9 \%$ & $12.0 \%$ & $11.5 \% 1$ & $10.5 \%$ & $9.1 \%$ & $7.4 \%$ & $5.3 \%$ & $100.0 \%$ \\
\hline \multicolumn{12}{|c|}{ Panel D. Momentum Characteristics } \\
\hline & \multicolumn{11}{|c|}{ Momentum } \\
\hline & Loser & 2 & 3 & 4 & 5 & 6 & 7 & 8 & 9 & Winner & Overall \\
\hline \multicolumn{12}{|l|}{ Universe: } \\
\hline $\begin{array}{l}\text { Average prior } \\
11 \text { month return }\end{array}$ & $-49.9 \%$ & $-27.7 \%$ & $6-14.7 \%$ & $6-4.6 \%$ & $4.2 \%$ & $13.0 \%$ & $22.5 \%$ & $634.7 \%$ & $53.8 \%$ & $109.4 \%$ & $14.1 \%$ \\
\hline \multicolumn{12}{|l|}{ Value Line Population: } \\
\hline $\begin{array}{l}\text { Average prior } \\
11 \text { month return }\end{array}$ & $-48.0 \%$ & $-27.3 \%$ & $6-14.5 \%$ & $6-4.6 \%$ & $4.3 \%$ & $13.0 \%$ & $22.5 \%$ & $634.7 \%$ & $53.5 \%$ & $104.8 \%$ & $18.1 \%$ \\
\hline Percentage of Firms & $4.9 \%$ & $7.6 \%$ & $9.4 \%$ & $10.6 \%$ & $11.5 \%$ & $12.0 \%$ & $12.1 \%$ & $611.8 \%$ & $611.1 \%$ & $9.1 \%$ & $100.0 \%$ \\
\hline
\end{tabular}

The statistics in Panel B indicate that there is a tendency for VL analysts to follow large capitalization stocks. For example, $54.4 \%$ of companies fall into the smallest size decile compared to only about $14.9 \%$ for the sample firms. The top three size deciles comprise $6.9 \%$ of the universe of firms; $18.8 \%$ of the sample firms are represented in these deciles.

At the same time, Value Line analysts also tend not to follow high book-to-market firms. The greater representation of growth firms is evident from Panel C. For example, only about $22 \%$ of the sample firms are concentrated in the highest three book-to-market deciles (relative to $30 \%$ in the universe). Finally, VL analysts show only a slight tendency to follow high momentum stocks. About $32 \%$ of the sample firms fall into the top three momentum deciles.

\section{How Do Value Line Analysts Compute Target Prices?}

Among the various statistics published in each weekly report, VL includes a four-year range of high and low target prices. VL analysts arrive at the high and low ranges by first calculating an expected four-year target price and then, based on historical price volatility, they calculate symmetric high and low deviations about the expected target. Since the expected returns that we construct are based on these target prices, we believe that it is important to provide additional information on the way in which we form these forecasts. 
The expected target price is calculated as the product of a forecasted price/earnings ratio and forecasted earnings per share, both of which are also provided in the VL report. We verify this with several conversations with Value Line representatives, examination of Value Line manuals (Value Line Methods, 1979), and reading of analyst reports dating back to the late 1950s (see also Ang and Peterson, 1985). This evidence is important, because it negates the possibility that some of the results that we obtain (such as the market beta positively associated with expected returns and market size negatively related with these expectations) arise because analysts have been deriving their expected return using CAPM as well as size related differences in realized returns. Indeed, our regression results hold even when we use only the first half of the sample (1975-1986, before the popularization of the CAPM) and it is unlikely that the results in the early part of the sample are simply an outcome of Business School education.

We emphasize that the models that we test here, be they the CAPM or Merton's ICAPM, lean heavily on Milton Friedman's (1953) "as if" methodological approach to modeling in economics, which has as its (only) goal of generating predictions which link expected rates of returns on financial assets with their risks. Indeed, the models intentionally abstract from the manner in which investors actually derive the necessary knowledge regarding the underlying economy to form these expectations. As a result, there is no explicit concern with investors' learning, which is in fact impossible to consider in a one-period CAPM. Similarly, the manner with which investors form their beliefs regarding future cashflows and risks is not held important for testing the models. Thus, whether investors form their expectations using simple rules of thumb or more sophisticated models is not a feature that the model is designed to explain.

\section{B. A Proxy for Ex Ante Expected Return}

As mentioned earlier, VL provides high and low ranges of expected prices which we average to re-create the point estimate of their expected four-year price. Since analysts actually send their report for publication for a given Friday on the Wednesday of the preceding week, we divide this price by the firm's market price that was outstanding nine days prior to the Value Line report date. (We convert all prices to the same split-adjusted basis.)

To account for the dividend yield component in the expected return calculation, we also add a prospective dividend yield term as follows. For the period 1975 through 1986, for each firm in the sample we first calculate estimates of the annual dividend yield and growth rates of dividends immediately prior to the calculation of the expected return. We calculate dividends as the sum of the dividends paid in the fiscal year before the price target is issued (Compustat data item \#21). Dividend growth rate is the ratio of current to prior year dividend per share given by Compustat (data item \#26), adjusted for stock splits. We then calculate the dividend yield as the estimated dividend for the next year relative to the end-of-year stock price. Interim dividends are reinvested at the firm's cost of capital, the variable we actually want to compute.

Therefore, we begin by calculating the following expression for the expected return. Equation (1) includes the future value of dividends, assuming that dividends will continue to grow at the same historical rate, $\mathrm{g}_{\mathrm{H}}$, in the following four years:

$$
\left(1+E R_{t}^{V L}\right)^{4}=\frac{T P_{t}}{P_{t-9}}+\left(\frac{D}{P}\right)_{H} \cdot\left(1+g_{H}\right) \cdot\left[\frac{\left(1+E R^{V L}\right)^{4}-\left(1+g_{H}\right)^{4}}{E R^{V L}-g_{H}}\right]
$$


where $T P_{t} / P_{t-9}$ is the expected return without the dividends. We then solve for the annualized expected return $E R_{t}^{V L}$ that satisfies this equality.

For the period 1987 through 2001, we obtain VL analysts' forecasts for both dividend growth rates and the next-year dividends. We use those estimates in calculating prospective dividend yield: ${ }^{7}$

$$
\left(1+E R_{t}^{V L}\right)^{4}=\frac{T P_{t}}{P_{t-9}}+\frac{\text { Div next year } \cdot\left[\frac{\left(1+E R^{V L}\right)^{4}-(1+g)^{4}}{E R^{V L}-g}\right]}{P_{t-9}}
$$

where $\mathrm{g}$ is the VL's forecasted dividend growth rate, $\mathrm{Div}_{\text {next year }}$ is the VL forecast of next year dividends. We then solve for the annualized expected return $E R_{t}^{V L}$ as in Equation (1) above. We note that we annualize the four-year Value Line expected return so as to make the results comparable to those using First Call expectations that we discuss in Section III. We obtain similar results when we replicate the asset pricing tests below using four-year expectations. Throughout the text we refer to this variable as the "annual expected return."

Table II presents statistics for the Value Line-based measure of expected return, $E R_{t}^{V L}$. For the stocks represented in this sample, the grand average annual expected return (across stocks and across years) is $21 \%$. Over the same time period, the median annual expected return is $19.4 \%$, the same order of magnitude as the average.

We note that we examine whether these expected returns have "reasonable" properties that are "model free," that is, that they correspond to a variation in a factor that is unambiguously related to expected returns. To this end we examine the cross sectional correlation of our expected return measure with leverage. Clearly, high leverage should lead to higher expected return, and that is what we find. The correlation between debt to equity ratio and expected return is positive and highly significant.

In Table II, we base the annual expected returns on equal-weighting of individual firm forecasts. Since value-weighting provides for a natural alternative to describe our data, in Figure 1 we present the time-series of value-weighted market expected returns. (We view the expected return on this value-weighted portfolio as an estimate of the expected return on the market portfolio.) For each period we value-weight all firms' expected return by their prior period market value of equity. Since firms receive coverage only once a quarter, we present estimates of market expectations on a quarterly basis for each end of quarter from 1975 through 2001. For example, the value-weighted expected return for March 1999 is the weighted average expected return of all stocks with a valid expected return on VL from January 1, 1999, to March 31, 1999. We observe that the value-weighted expected return is lower than its equal-weighted equivalent. For the VL series, the average value-weighted expected return is $17.8 \%$ compared to the equal weighted return of $21 \% .{ }^{8}$ The decline in the market expected return over our sample period is similar to that reported by Jagannathan, McGrattan, and Scherbina (2000) and Fama and French (2001).

\footnotetext{
${ }^{7}$ We checked the sensitivity of the results to different assumptions regarding the next-year dividends (including zero dividends in the future) and dividends' growth rates, and find that alternative specifications have little impact on the coefficients' point estimates and no impact on any of the inferences.

${ }^{8}$ In unreported analysis, we assess the frequency of quarterly target price revisions. We find that the probability that, on average, a VL analyst revises his price forecast in the ensuing 1, 2, 3, and 4 quarters are 61, 87, 95, and $97 \%$, respectively.
} 
Table II. Descriptive Statistics of Value Line's Annual Expected Return

This table provides summary statistics on the distribution of Value Line's expected annual return by year. We calculate the expected return as the ratio of the Value Line target price and the firm's market price that was outstanding nine days before the Value Line report date. We use market price nine days before the Value Line report date, since analysts actually send their report for publication on a given Friday on the Wednesday of the preceding week. For the period 1975-1986, we adjust for expected dividend payments by calculating the growth rate of dividends and the dividend yield immediately preceding the report date. We assume that dividends are reinvested at the firm cost of capital. For the period 1987-2001, we use Value Line analysts' forecasts of dividend growth rates and forecasts of the next year dividends, again reinvesting interim dividends at the firm cost of capital. We winsorize the target price to stock price ratio at the 1st and the 99th percentiles to mitigate the potential effects of extreme observations. Equations (1) and (2) in the text provide the calculation of the expected return.

\begin{tabular}{lcccccc}
\hline \hline Year & Mean & Q1 & Median & Q3 & Std Deviation & $\mathbf{N}$ \\
\hline 1975 & 0.341 & 0.245 & 0.325 & 0.427 & 0.130 & 5,579 \\
1976 & 0.297 & 0.221 & 0.286 & 0.365 & 0.108 & 5,058 \\
1977 & 0.281 & 0.215 & 0.275 & 0.345 & 0.095 & 5,862 \\
1978 & 0.279 & 0.217 & 0.276 & 0.336 & 0.090 & 5,871 \\
1979 & 0.307 & 0.238 & 0.307 & 0.376 & 0.102 & 5,968 \\
1980 & 0.310 & 0.227 & 0.314 & 0.392 & 0.121 & 5,804 \\
1981 & 0.282 & 0.219 & 0.282 & 0.345 & 0.094 & 5,984 \\
1982 & 0.310 & 0.243 & 0.307 & 0.373 & 0.097 & 6,015 \\
1983 & 0.194 & 0.149 & 0.200 & 0.244 & 0.075 & 5,060 \\
1984 & 0.228 & 0.182 & 0.225 & 0.271 & 0.073 & 5,615 \\
1985 & 0.196 & 0.148 & 0.191 & 0.239 & 0.079 & 4,993 \\
1986 & 0.149 & 0.106 & 0.146 & 0.189 & 0.072 & 5,194 \\
1987 & 0.147 & 0.099 & 0.138 & 0.189 & 0.078 & 5,292 \\
1988 & 0.187 & 0.141 & 0.180 & 0.227 & 0.073 & 5,395 \\
1989 & 0.168 & 0.125 & 0.163 & 0.206 & 0.070 & 5,245 \\
1990 & 0.211 & 0.144 & 0.197 & 0.262 & 0.092 & 5,196 \\
1991 & 0.191 & 0.130 & 0.179 & 0.239 & 0.085 & 5,202 \\
1992 & 0.175 & 0.117 & 0.167 & 0.221 & 0.080 & 5,184 \\
1993 & 0.148 & 0.097 & 0.144 & 0.192 & 0.072 & 5,292 \\
1994 & 0.157 & 0.111 & 0.154 & 0.196 & 0.066 & 5,184 \\
1995 & 0.149 & 0.107 & 0.144 & 0.185 & 0.061 & 5,174 \\
1996 & 0.136 & 0.091 & 0.129 & 0.173 & 0.065 & 5,067 \\
1997 & 0.121 & 0.079 & 0.114 & 0.156 & 0.062 & 5,101 \\
1998 & 0.128 & 0.070 & 0.115 & 0.172 & 0.081 & 5,100 \\
1999 & 0.156 & 0.095 & 0.149 & 0.209 & 0.087 & 5,328 \\
2000 & 0.187 & 0.116 & 0.183 & 0.251 & 0.103 & 5,645 \\
2001 & 0.174 & 0.110 & 0.160 & 0.222 & 0.093 & 5,771 \\
$1975-2001$ & 0.210 & 0.132 & 0.194 & 0.277 & 0.110 & 146,179 \\
& & & & & & \\
\hline \hline
\end{tabular}

\section{Cross-Sectional Variation in Ex Ante Expected Returns}

In this section, we ask whether variation in expected equity returns is related to the firms' factor loadings on different sets of factors that have been proposed in the literature. We examine three such asset-pricing model specifications: the Sharpe-Lintner CAPM, the Fama and French (1993) 

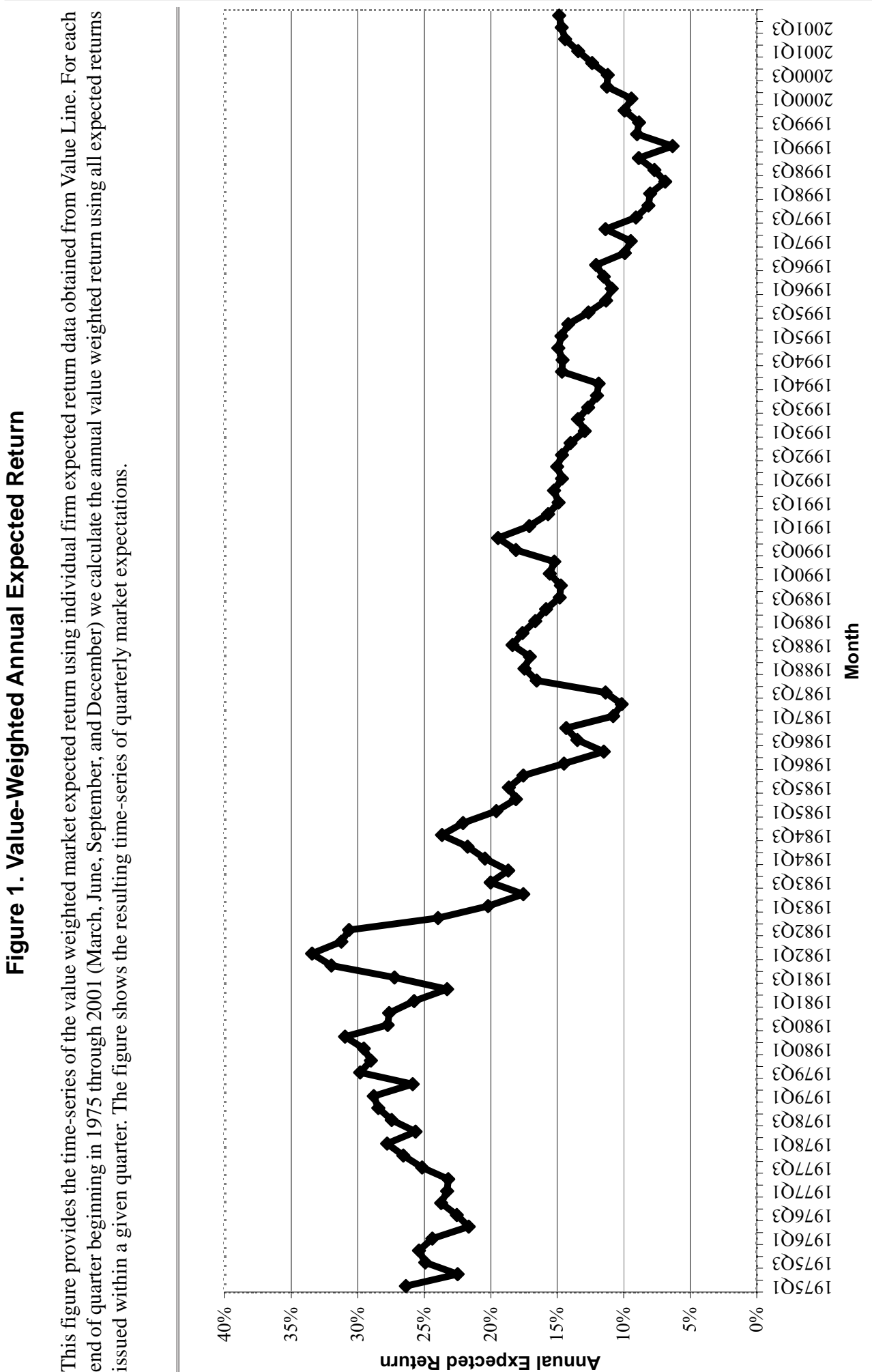
three-factor model, and Carhart's (1997) four-factor model. ${ }^{9}$

To establish a useful benchmark, we also follow Fama and French (1992) and conduct Fama-MacBeth cross-sectional regressions in which the dependent variable is realized monthly return for the Value Line sample for the period 1975 through 2001. As in Fama and French, we find that the market beta is associated with an insignificant premium, but there is a statistically significant negative (positive) relation between firm size (book-to-market ratio) and realized returns. Realized returns have a positive and significant association with prior price momentum.

The basic asset-pricing question is whether expected returns are determined by firm factor loadings. There are two common approaches to estimating the factor loadings. The first is to directly estimate the covariance between the factor return and stock return by using historical data. The second is to use a proxy, such as size and book-to-market, for the factor loadings. This approach assumes that the researcher can obtain a better proxy for actual covariances by using the characteristics rather than by historical estimation. ${ }^{10}$ Since it is not our objective here to take a stand on which approach is preferred, we simply present the results using both factors and characteristics.

Our tests are based on Fama and MacBeth's (1973) methodology. First, we estimate firmspecific factor loadings on the size and book-to-market factor in a given month by using the preceding 60 months. We require a minimum of 24 months with valid data for the estimation. Since VL provides their estimated market betas for each stock, we use this beta rather than the one estimated with the procedure described above. ${ }^{11}$ Second, for every month from January 1975 through December 2001, we regress firms' expected annual excess return $\left(E R_{t}^{V L}\right.$ $\mathrm{R}_{\mathrm{f}}$ ) on their estimated factor loadings and on their characteristics. Following Froot and Frankel (1989), we interpret the regression error as random error in analysts' expectations. We report the average of the estimated intercept and slope coefficients and their associated $t$-statistics for various model specifications. We compute the $t$-statistics by using standard errors that allow for the possibility that the estimated factor premia are serially correlated (see Pontiff, 1996). This is likely to be the case, since analyst expectations are serially correlated. We first estimate an autoregressive model for the time-series of the factor premia and then derive standard errors that are consistent with the estimated structure. We provide the details in the Appendix. ${ }^{12}$

We begin our tests of the CAPM by regressing the expected excess return on the firm's market beta. The results, presented in Table III, Column 1, indicate that the estimate of the annual market premium is positive and highly significant $(t$-statistic=5.1). Its magnitude is economically reasonable with a point estimate of $6.7 \%$. In light of recent evidence that beta cannot explain variation in ex post returns (Fama and French, 1992), the positive and significant coefficient on beta is particularly important. Our evidence shows that stocks' expected returns are in fact related to their systematic exposure to the market, and that the relation is both

${ }^{9}$ Fama and French's empirical model includes RMRF, the excess return on the value-weighted market portfolio, $\mathrm{SMB}$, the return on a zero investment portfolio formed by subtracting the return on a large firm portfolio from the return on a small firm portfolio, and HML, the return on a portfolio of high book-to-market stocks less the return on a portfolio of low book-to-market stocks. Carhart's model includes a fourth factor, PR12, which is formed by taking the return on high return stocks minus the return on low return stocks over the preceding year.

${ }^{10}$ See Reisman $(1992,2001)$ for a theoretical justification for this approach.

${ }^{11}$ In the next section, we examine the sensitivity of our results to alternative measures of market beta.

${ }^{12} \mathrm{We}$ also conduct inferences on the regression estimates using Newey-West standard errors. Inferences using these standard errors yield lower coefficient standard errors in all regression specifications and thus more powerful rejections. We chose to present inferences that are more conservative. 


\section{Table III. Fama-MacBeth Regressions Based on Value Line Estimates of One- Year Expected Excess Return, 1975-2001}

This table presents the time-series averages of 324 slopes from month-by-month regressions of one-year expected excess returns on a set of estimated factor loadings (Panel A) or firm characteristics (Panel B). The one-year expected excess return is equal to the difference between the Value Line expected return estimate $\mathrm{ER}^{\mathrm{VL}}$ described in Section I.B, and the one-year risk free rate obtained from the Fama-Bliss files on CRSP. We estimate factor loadings for month $t$ by using data from month $\mathrm{t}-61$ through $\mathrm{t}-1$. Doing so requires a minimum of 24 valid monthly returns. Since Value Line provides a firm-specific market beta in each report, we replace the estimated market beta with the one reported by Value Line. We compute the size in month $\mathrm{t}$ as the log of market capitalization measured as of the end of the previous June (expressed in millions of dollars). We compute book-to-market as the ratio of annual common shareholders equity (Compustat item \#60) to market capitalization as of the end of the fiscal year. We apply the log of this ratio to the 12-month period beginning six months subsequent to the end of the fiscal year. Prior price momentum for month $t$ is the buy-and-hold return for the 11-month period ending one month prior to month $\mathrm{t}$. We winsorize monthly observations at the $1^{\text {st }}$ and $99^{\text {th }}$ percentiles to mitigate the possible effect of extreme observations. The $t$-statistics adjusted for the overlapping nature of the data are the ratio of the time-series average divided by the estimated time-series standard error. (See Appendix for the details.)

\begin{tabular}{|c|c|c|c|}
\hline \multicolumn{4}{|c|}{ Panel A. Regressions of One-Year Expected Excess Return on Factor Loadings } \\
\hline & Model I & Model II & Model III \\
\hline \multirow[t]{2}{*}{ Intercept } & 0.068 & 0.068 & 0.067 \\
\hline & 3.2 & 3.7 & 4.2 \\
\hline \multirow[t]{2}{*}{$\beta$} & 0.067 & 0.058 & 0.057 \\
\hline & 5.1 & 4.7 & 4.4 \\
\hline \multirow{2}{*}{$\gamma_{\mathrm{SMB}}$} & & 0.016 & 0.016 \\
\hline & & 2.1 & 2.1 \\
\hline \multirow[t]{2}{*}{$\gamma_{\mathrm{HML}}$} & & 0.002 & 0.001 \\
\hline & & 0.4 & 0.2 \\
\hline \multirow[t]{2}{*}{$\gamma_{\mathrm{PMOM}}$} & & & -0.021 \\
\hline & & & -3.0 \\
\hline Average Adjusted $\mathrm{R}^{2}$ & $5.9 \%$ & $12.2 \%$ & $13.8 \%$ \\
\hline Average Monthly N & 443 & 435 & 428 \\
\hline \multicolumn{4}{|c|}{ Panel B. Regressions of One-Year Expected Excess Return on Firm Characteristics } \\
\hline & Model I & Model II & Model III \\
\hline \multirow[t]{2}{*}{ Intercept } & 0.068 & 0.119 & 0.125 \\
\hline & 3.2 & 5.3 & 5.3 \\
\hline \multirow[t]{2}{*}{$\beta$} & 0.067 & 0.078 & 0.076 \\
\hline & 5.1 & 7.3 & 6.1 \\
\hline \multirow[t]{2}{*}{$\log ($ Size $)$} & & -0.010 & -0.009 \\
\hline & & -2.6 & -2.5 \\
\hline \multirow[t]{2}{*}{ log(Book-to-Market) } & & 0.012 & 0.010 \\
\hline & & 1.8 & 1.8 \\
\hline \multirow[t]{2}{*}{ Prior Return } & & & -0.096 \\
\hline & & & -11.5 \\
\hline Average Adjusted $\mathrm{R}^{2}$ & $5.9 \%$ & $13.4 \%$ & $26.0 \%$ \\
\hline Average Monthly N & 443 & 406 & 401 \\
\hline
\end{tabular}


economically and statistically significant. ${ }^{13}$

Next, in Column 2 we present estimates of factor premiums for the Fama and French threefactor model. We find that the estimate of the market premium drops slightly to $5.8 \%$ on an annual basis, but is still highly significant. The factor loading on size is also priced, and has a slope coefficient equal to $1.6 \%$ annually $(t$-statistic=2.1). Thus, even after controlling for market beta, the size premium is positive and significant, consistent with the findings of many studies that use ex post returns. In other words, holding market risk constant, investors expect small firms to generate higher returns than large firms.

The estimated premium related to covariation with the book-to-market factor, $\gamma_{\mathrm{HML}}$, is statistically insignificant. This estimate equals $0.2 \%(t$-statistic $=0.4)$, suggesting that investors do not expect value stocks (high book-to-market) to yield higher returns than growth (low book-to-market) stocks because they are riskier. This result is not consistent with the implications drawn from empirical studies that use securities' ex post returns (Fama and French, 1992), which interpret the positive relation between book-to-market ratio and ex post returns as evidence in favor of an additional systematic risk factor.

Column 3 of Table III presents results for the four-factor model (including momentum as the fourth factor). We find that market and size factors are still associated with positive and significant premiums. Consistent with the results presented earlier, the premium demanded on the book-to-market factor is not significant. The estimate of the premium associated with the momentum factor, $\gamma_{\mathrm{PMOM}}$, is negative $(-2.1 \%)$ and significant. This implies that investors condition their expected return on past price trajectory, but in exactly the opposite direction of what researchers find when they use ex post returns (e.g., Jegadeesh and Titman, 1993). Our results indicate that investors, or at least Value Line analysts, do not consider recent winner stocks as riskier and thus do not require higher expected returns relative to recent loser stocks. ${ }^{14}$

The regression results also reveal a systematic pattern in expectations that cannot be entirely explained by any of the models that we use. The positive and significant intercept (about $6.8 \%$ in all regressions) is consistent with the notion that there are other factors missing from our specifications. It is also interesting to note that the $\mathrm{R}^{2}$ of the factor regressions are larger by order of magnitude than what is reported when the dependent variable is realized return. On the other hand, the fact that our $\mathrm{R}^{2}$ does not equal $100 \%$ indicates that either we have likely measured the market's expectations with noise, or that we have an incomplete model of how expectations are formed, or both. But overall, current factor models are better able to explain the cross-sectional variation in expected returns than in realized returns.

As we discussed earlier in the article, a priori it is unclear whether estimates of factor loadings using historical data or proxies for the factor loadings using firms' characteristics better capture covariation of firm returns with systematic factors. Panel B, Table III, presents the regression results with firms' characteristics as the independent variables.

\footnotetext{
${ }^{13}$ In unreported results, we follow Jagannathan and Wang (1996) and test a conditional version of the CAPM. Jagannathan and Wang show that the conditional CAPM implies an unconditional two-factor model in which expected returns are linearly related to market beta and what they coin a measure of "beta instability." We compute individual firm betas with respect to both the market portfolio and the default yield spread and use these "full sample" betas within the Fama-MacBeth regression specification. We find that the slope on the additional beta ( $b^{\text {prem }}$ in Jagannathan and Wang, 1996) is indeed positive but statistically insignificant.

${ }^{14}$ Since Value Line analysts estimate a four-year expected return, in isolation, this result seem to be consistent with the De Bondt and Thaler's (1985) winners and losers phenomena. However, the First Call analysts estimate only one year ahead expected return and we find similar results there as well (See Section III.A).
} 
We estimate the three-characteristics model (Model II in Panel B) using market beta along with (log of) size and (log of) book-to-market. The results show that investors expect small firms' returns to be significantly higher than those of large firms. This result is consistent with what we find when the factor loadings are the explanatory variables. It is also consistent with the findings of Banz (1981), Reinganum (1981), and Fama and French (1992) when they use the dependent variable as the ex post realized return - that is, on average, small stocks' returns turn out to be higher than large stocks' returns. (When we examine whether alternative measures of firm size, such as sales and total assets, are also negatively related to firm expected returns, we obtain similar evidence when we use these alternative measures in the characteristics-based regressions.)

Contrary to the finding of studies that use ex post returns, but just like the results in Panel A, the premium associated with book-to-market is insignificant. The coefficient on prior return is negative and significant (Model III in Panel B). The negative coefficient suggests that annual expected returns are higher for past losers than for past winners. This result is surprising. First, it contrasts with what we observe when realized returns are used for this short time horizon (e.g., Jegadeesh and Titman, 1993). Second, it is not intuitive to reconcile this result with Jegadeesh, Kim, Krische, and Lee (2004), who find that analysts tend to follow momentum stocks. If analysts tend to follow momentum stocks, it may be because they believe those stocks will generate higher returns. But then why do we observe that their expected return is negatively affected by momentum? One possibility is that our expected return measure also contains expectations from the beginning of the month, which may artificially create this negative relation. We check for this possibility and find no evidence that this is the cause of the relation.

To summarize, the use of expected returns derived from independent analysts' estimates leads to three important results. First, while the CAPM is rejected, market risk is priced. Cross-sectionally, expected return is positively related to beta. Second, holding market beta constant, the expected return on small stocks is significantly higher than the expected return on large capitalization stocks. Third, we do not find evidence that high book-to-market stocks are associated with a higher expected return. This evidence is inconsistent with the view that book-to-market is a risk factor in the traditional sense. If such stocks were indeed riskier, then investors would have expected them to earn higher returns. ${ }^{15}$

Figure 2 illustrates these findings. Over the period 1975 to 2001, we calculate for each firm an average of all outstanding expected annual excess returns as well as the average market betas and slopes on the Fama and French size factor, SMB. We then form independent decile breakpoints by beta and slopes on SMB and allocate all firms into one of the resulting 100 portfolios. We estimate a cross-sectional regression in which we regress the portfolio expected excess returns against their average betas and size-related factor loadings. The plot provides both the portfolio expected excess returns and the fitted plane from the least squares regression. The plot clearly illustrates our finding that market-related risk is positively priced. Furthermore, when we control for market risk, the higher premium for size-related risk is also evident.

\footnotetext{
${ }^{15}$ In unreported results, we also examined an alternative measure of risk provided by VL. Specifically, VL assigns each firm a safety rank, which they define as "a measure of the potential risk of a stock investment." This measure ranges from 1 (the highest safety and lowest risk) to 5 (the lowest safety and highest risk). We find that the VL expected returns covary positively with this measure, holding market beta and firms size constant. We leave it for future research to examine the interplay of this measure with the more standard measures of risk.
} 


\section{Figure 2. Expected Return and Firm Exposures to Market- and} Size-Related Factors

The figure provides cross-sectional regression results based on 100 portfolios, which we sort by market beta and factor loadings on a size-related factor mimicking portfolio. Using Value Line expectations, we average individual firm annual expected excess return over the sample period 1975-2001 as well as their market betas and factor loadings on the Fama and French (1993) SMB portfolio. We then form decile cutoffs based on the latter factor loadings and allocate all firms into one of the resulting 100 portfolios. We estimate a cross-sectional regression in which the dependent variable is the portfolios' annual expected excess return and the independent variables are the portfolios' average loadings. The regression yields the following estimates: $\mathrm{E}(\mathrm{r})-\mathrm{R}_{\mathrm{f}}=0.06+0.04 \beta+0.02 * \mathrm{SMB}$. We plot the portfolio expected excess returns and the regression plane associated with the least squares estimation.

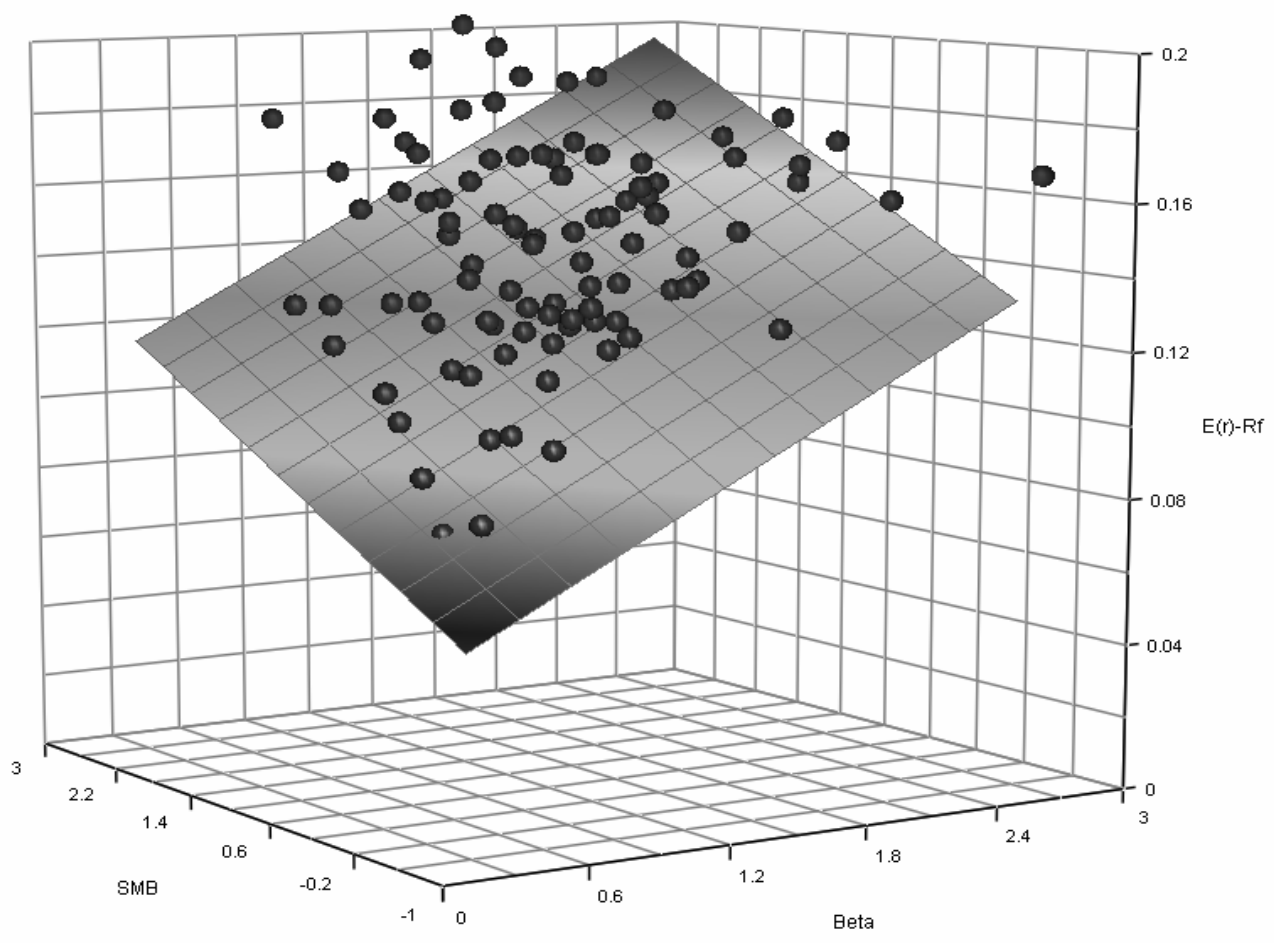

\section{An Alternative Set of Expected Returns}

While Value Line services are subscribed to by an array of both individuals and institutions, we find it prudent to use another set of expectations and to examine whether the relation between expected return and the factors is unique to the Value Line estimates of expected returns. We construct an expected return measure based on First Call's database (hereafter, FC), which gathers target prices issued by sell-side analysts. We use FC's one-year-ahead target price forecasts for 
over 7,000 firms during the period 1997 through $2001 .{ }^{16}$ By using these target price forecasts, we can calculate analysts' annual expected returns for these stocks.

The information provided by FC is widely disseminated to all major institutional investors as well as many other investors, including individuals, and empirical evidence shows that analysts' opinions affect prices (Womack, 1996, Barber, Lehavy, McNichols, and Trueman, 2001, and Brav and Lehavy, 2003). Another advantage of this set of expectations is that a typical stock receives a target price from more than one analyst (on average, there is a target price from eight analysts per stock). As a result, the average (or the median) FC target price is likely to be less noisy and thus better reflect the consensus opinion.

On the other hand, a potential concern with sell-side analysts' expectations and recommendations is that they are biased (e.g., Rajan and Servaes, 1997, Michaely and Womack, 1999, and Barber, Lehavy, and Trueman, 2005) and that their forecasts may not accurately represent market expectations. Despite the clear bias in sell-side analysts' expectations, these expectations may still be correlated with those of investors. For example, using a UBS/Gallup monthly telephone survey of individual investors over the period 1998 through 2002, Vissing-Jorgensen (2003) reports a similar time series pattern in individuals' expected market return to our findings using First Call analysts' expected return.

Panel A of Table IV provides descriptive statistics on the FC target price database. 1997 is the first year with complete target price data (coverage begins in November 1996 with 3,862 target price reports for that year). Coverage increases over time from about 49,000 price target reports in 1997 to about 92,000 reports in 2001 . The average number of price targets per covered firm (Column 3) also increases from 11 in 1997 to 23 in 2001. The target price database is comprehensive and includes reports for 7,073 firms. The number of participating brokerage houses remains fairly constant over the years, with an increase from 125 in 1997 to 140 in 2001 (Column 5), with 229 distinct brokerage houses issuing price target reports across all years. Over the time period we analyze, on average, eight brokerage houses cover each firm in the sample. In our analysis we include only firms with ordinary shares (CRSP share codes 10 and 11). We find that these firms account for approximately $97 \%$ of the total market value of all securities with ordinary shares on CRSP.

In Table IV, Panels B through D describe the size, book-to-market, and prior price momentum characteristics of our sample firms relative to the universe of firms available on CRSP (the variables' definitions and the construction of the decile portfolios are described in Section I.A.). The statistics in Panel B indicate that FC analysts cover fewer small firms (decile 1) than is representative from the broad universe. For example, $49 \%$ of companies fall into the smallest size decile compared to only $32.5 \%$ for the sample firms. In all other deciles the percentage of firms from FC is slightly larger than the broad universe. This evidence indicates that this sample is tilted toward larger firms.

In Panel C, we report similar statistics for our book-to-market sorts. There is some tendency for analysts to follow high-growth, low book-to-market firms and avoid value, high book-tomarket firms. In Panel D, we see that there is a slight tendency for analysts to avoid loser stocks, low momentum stocks, with $8.6 \%$ of the sample firms falling in the bottom decile. ${ }^{17}$

To construct the expected return, $\mathrm{ER}^{\mathrm{FC}}$, we begin by excluding individual target prices

\footnotetext{
${ }^{16}$ In $94 \%$ of the reports, analysts explicitly state a 12 -month horizon for the price target. In another $3 \%$ of the reports the horizon was 18 months, and we annualized it to 12 months horizon. In $3 \%$ of the reports the time horizon was not stated and it was assumed to be 12 months. Using only the portion of the sample with explicit mention of 12-month horizon yield identical results to what reported in this section.

${ }^{17}$ Stickel (2001), and Jegadeesh, Kim, Krische, and Lee (2002) find similar characteristics for analyst stock recommendations.
} 


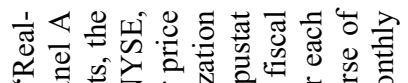

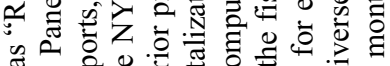

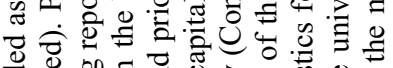

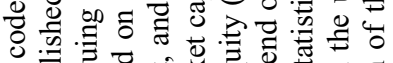

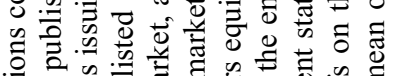
은

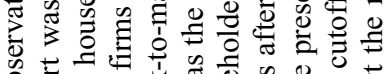

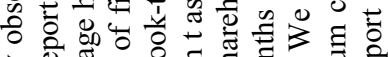

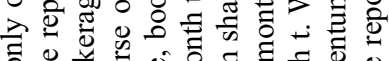

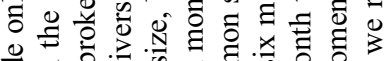

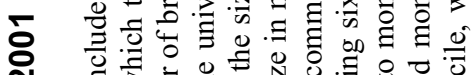
ণิ

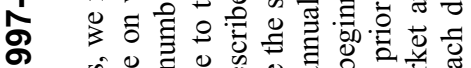

ㅇ so

i t)

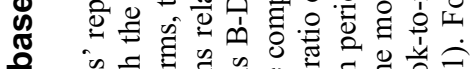

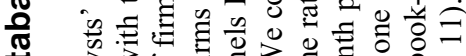

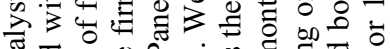

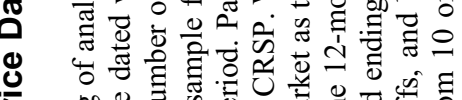

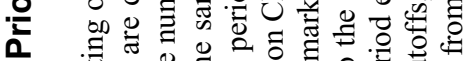

능

๙

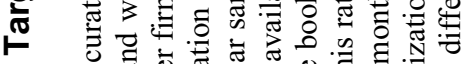

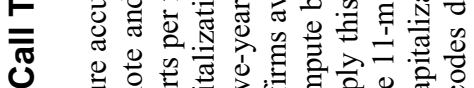

0

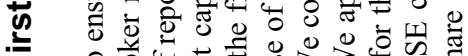

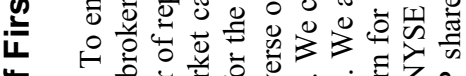

○一

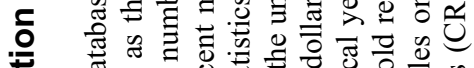

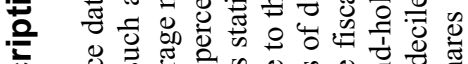

o 0

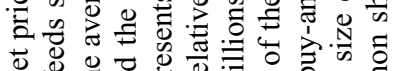

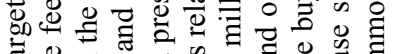

¿

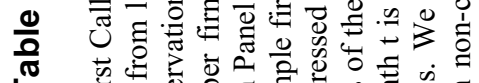

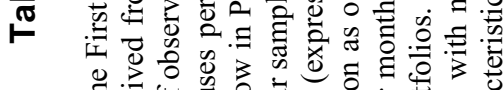

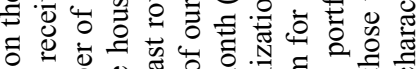

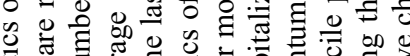

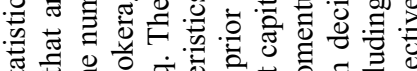

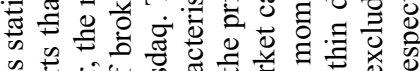

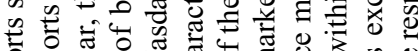

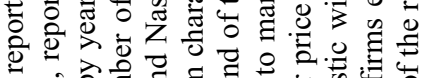
列古

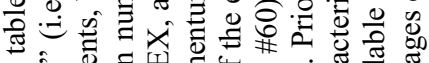
क.

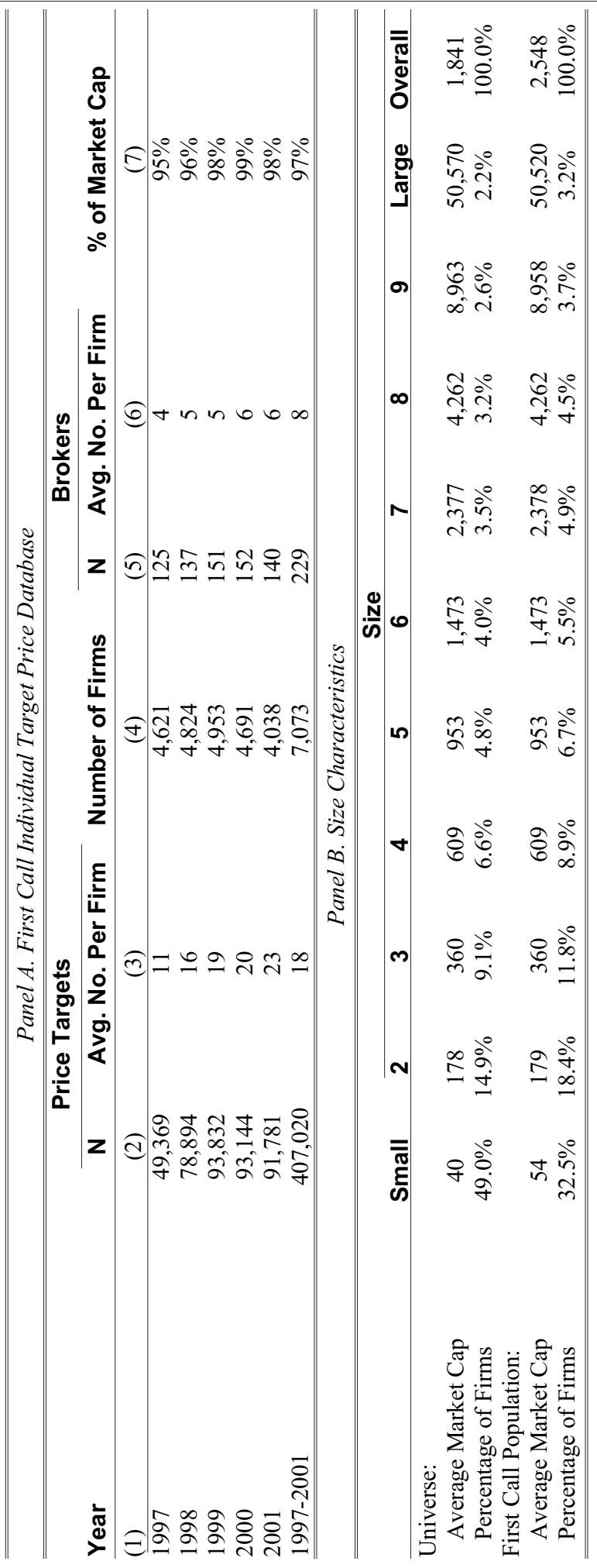




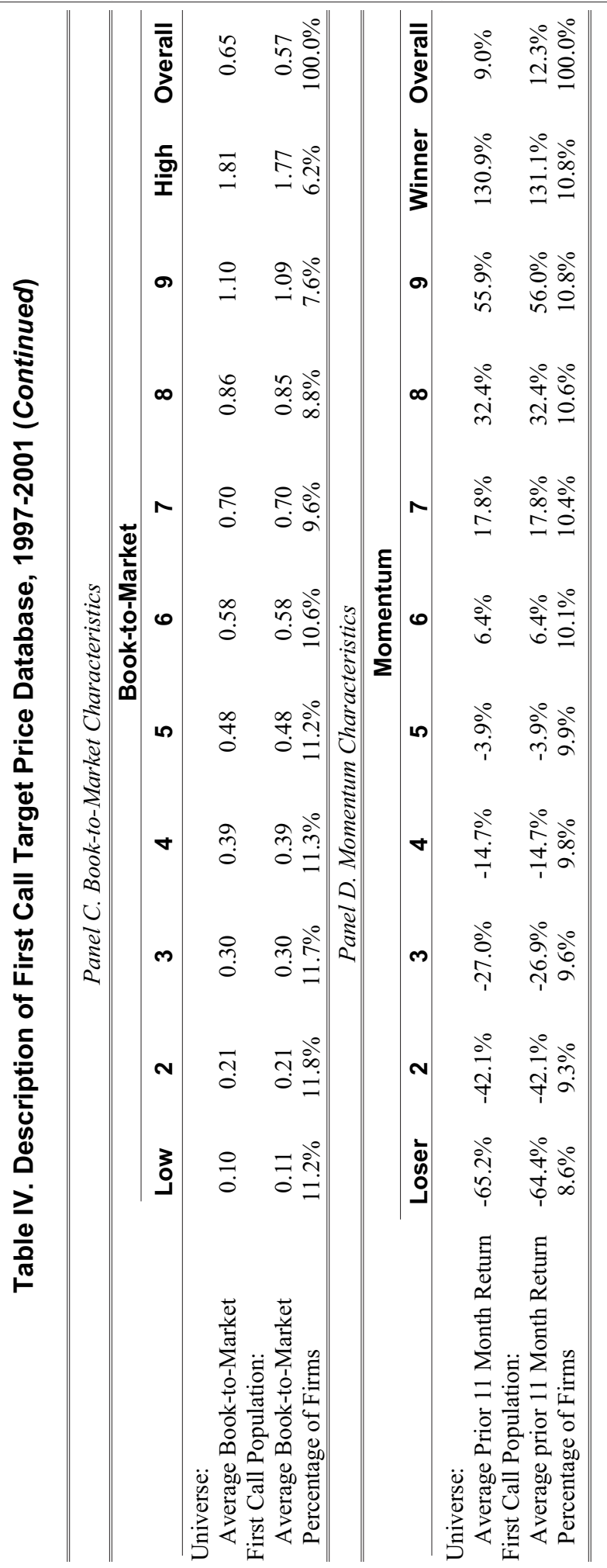


outstanding for more than 30 days. Next, in any given month over the period 1997 through 2001 we calculate the ratio of each individual analyst target price to the stock price outstanding two days prior to the announcement of the individual target price (We convert all prices to the same split-adjusted basis.) For any given month we average the individual analysts' expectations to obtain the consensus expected return.

To account for the dividend yield component in the expected return calculation we also add a prospective dividend yield term as follows. For every firm in the sample we first calculate estimates of annual dividends and growth rates of dividends immediately before we calculate the expected return. We calculate dividends as the sum of the dividends paid in the fiscal year before the price target is issued (Compustat data item \#21). We define dividend growth rate as the ratio of current to prior year dividend per share (Compustat data item \#26), adjusted for stock splits. We calculate the dividend yield as the estimated dividend next year relative to the price two days prior to the issuance date of the price target. The adjustment to the expected return is then the product of the dividend yield and (one plus) the growth rate, g, of dividends: ${ }^{18}$

$$
1+E R_{t}^{F C}=\frac{T P_{t}}{P_{t-2}}+\frac{\text { Div }_{\text {current }}(1+g)}{P_{t-2}}
$$

where $T P_{t} / P_{t-2}$ is the stock's consensus expected return without the dividends.

\section{A. Regression Results based on First Call Expected Returns}

Before reporting the regression results, we provide some summary statistics on the First Call expected returns (not reported in our tables). For the period 1997-2001, the average annual expected return across all stocks in the FC sample is $45 \%$. The average $\mathrm{ER}^{\mathrm{FC}}$ increases from $33 \%$ in 1997 to $56 \%$ in 2000 , but decreases to $46 \%$ in 2001 . This trend coincides with the general market increase and subsequent reversal. Comparing the annual expected return of FC analysts to that of VL suggests that VL analysts have significantly lower expectations of returns than do sell-side analysts. As we show later, this difference is not driven by the slightly different set of covered companies nor by the different time frames of the samples.

Table V presents regression results for a four-factor model specification using First Call expected returns. (For brevity, we do not report regression results for the CAPM and the Fama and French (1993) three-factor model, since estimated factor premiums within these models are similar to those with a four-factor model specification.) Our results indicate that the estimate of the annual market premium is positive and significant $(t$-statistic $=4.3)$. The point estimate of $7 \%$ is similar to what we find using the Value Line expected return. The estimate of the intercept implies an abnormal annual return of $20.3 \%$, much higher than what has been found using Value Line expected return (an intercept of 6.7\%). It is likely that the difference captures sell-side analysts' systematic tendency to issue overly optimistic expected return estimates.

The factor loading on size is priced as well with a slope coefficient equal to $11.1 \%$ annually $(t$-statistic $=7.1)$. The estimated premium related to covariation with the book-to-market factor, $\gamma_{\mathrm{HML}}$, is negative and insignificant. This estimate equals $-6.3 \%(t$-statistic $=-1.5)$. The estimate of the premium associated with the momentum factor, $\gamma_{\text {РмOM }}$, is negative $(-1.3 \%)$ but

\footnotetext{
${ }^{18}$ The average dividend growth rate for the firms in our sample period is $6 \%$.
} 


\section{Table V. Fama-MacBeth Regressions Based on First Call Estimates of One-Year Expected Return, 1997-2001}

This table presents the time-series averages of 60 slopes from month-by-month regressions of one-year expected excess returns on a set of estimated factor loadings and/or firm characteristics. The one-year expected excess return is equal to the difference between the First Call expected return estimate $\mathrm{ER}^{\mathrm{FC}}$, which we describe in Section III, and the one-year risk free rate obtained from the Fama-Bliss files on CRSP. We estimate the factor loadings for month $\mathrm{t}$ by using data from month $\mathrm{t}-61$ through $\mathrm{t}-1$ (requiring a minimum of 24 valid monthly returns). We compute the size in month $t$ as the $\log$ of market capitalization measured as of the end of the previous June (expressed in millions of dollars). We compute book-to-market as the ratio of annual common shareholders equity (Compustat item \#60) to market capitalization as of the end of the fiscal year. We apply the log of this ratio to the 12-month period beginning six months subsequent to the end of the fiscal year. Prior price momentum for month $t$ is the buy- and-hold return for the 11-month period ending one month prior to month $\mathrm{t}$. We winsorize monthly observations at the 1st and 99th percentiles to mitigate the possible effect of extreme observations. The tstatistics adjusted for the overlapping nature of the data are the ratio of the time-series average divided by the estimated time-series standard error. (See Appendix for the details.)

\begin{tabular}{lclc}
\hline \hline & Factor Loadings & & \multicolumn{2}{c}{ Characteristics } \\
\hline Intercept & 0.203 & Intercept & 0.592 \\
& 5.8 & & 11.2 \\
$\beta$ & 0.070 & $\beta$ & 0.109 \\
$\gamma_{\mathrm{SMB}}$ & 4.3 & $\log ($ Size $)$ & 3.7 \\
& 0.111 & $\log ($ Book-to-Market $)$ & -0.058 \\
$\gamma_{\mathrm{HML}}$ & 7.1 & & -12.8 \\
& -0.063 & Prior Return & -0.035 \\
$\gamma_{\mathrm{PMOM}}$ & -1.5 & & -4.5 \\
& -0.013 & & -0.091 \\
& -1.1 & Average Adjusted $\mathrm{R}^{2}$ & -5.1 \\
Average Adjusted $\mathrm{R}^{2}$ & $13.8 \%$ & Average Monthly N & $16.5 \%$ \\
Average Monthly N & 1,779 & & 1,626 \\
\hline
\end{tabular}

insignificant with a $t$-statistic of -1.1. The characteristic regressions yield similar results: a positive market beta coefficient; a negative size coefficient, indicating that small cap stocks have higher expected returns than large cap stocks; a negative and significant book-tomarket coefficient, implying that growth stocks (low BM) have higher expected returns than value stocks (high BM); and negative (and significant) coefficient on prior return.

The similarities between the Value Line expected return results and the First Call expected return results are striking. Perhaps the most important feature is that beta is priced for both sets of expectations. Both databases also indicate that investors expect small stocks to earn higher returns than large stocks. We can also infer that high book-to-market is not associated with higher predicted returns. If anything, value stocks have lower expected return than growth stocks.

To ensure that our comparison of the results in Table III (Value Line) with those in Table V (First Call) is valid and not driven by differences in the time period examined or in the firms covered, we repeat the experiment using only firms that are covered by both databases, and for the time period when they both covered those stocks. This constraint restricts the sample to the period 1997-2001. However, our results do not change materially: the market beta and SMB beta coefficients are positive and significant; the HML beta is negative, but significant only for the First Call sample; and the momentum beta is negative. 
To check the integrity of the First Call results, we conduct several additional robustness tests. In the first test, we use only the most recently issued price target in any given month to ensure that staleness of price target does not affect our results. In the second test, we use the median, instead of consensus price target to calculate expected return. In the third test, we use only new price targets and not a reiteration of the old price targets. None of our results change.

In an unreported analysis, we conduct two tests designed to illuminate the impact of sellside analysts' bias on the relation between expected returns and pricing factors. In the first test, each month we divide the First Call sample into two groups. The first group consists of firms whose consensus stock recommendation is a "Hold" or lower; the second group comprises firms whose consensus recommendation is a "Buy" or higher. Since analysts issue pessimistic recommendations for stocks in the Hold group, it is less likely that they have a positive bias toward these stocks. We then conduct the Fama-MacBeth regressions for the firms in the two groups separately. If analysts' bias is the driving force behind our results, we expect our results to disappear (or weaken) for the group of stocks with a hold recommendation or lower. However, we find that the main difference across the two groups is the magnitude of the intercept, which is significantly higher for firms whose consensus recommendation is Buy or higher. We do not find differences in the association between expected excess return and pricing factors for both subsamples. This finding suggests that it is unlikely that our results are an artifact of this bias.

Our second test is based on the idea that analysts have an incentive to issue overly optimistic target prices for firms that are involved in raising capital, since doing so may increase the likelihood that their investment bank will underwrite these offerings. Hence, the bias for firms raising capital is likely to be higher. We use a naïve model of expectations in which we assume that on average, analysts correctly assess the occurrence of an equity issue in the coming year. Thus, we divide the sample into two portfolios. The first portfolio comprises firms that either had an equity offering in the previous year or will have an equity issue in the next year. The second portfolio contains the remaining firms. If analysts' bias is correlated with such a corporate activity, we expect to find a bias for stocks of firms that raise capital. We obtain information for both initial and seasoned equity offerings from Security Data Corporation. As with the first test, we find that the bias in analysts' forecasts affects the magnitude of the regression intercept but does not have a material effect on the slope coefficients.

\section{Robustness}

In this section, we perform additional robustness tests. First, we examine the sensitivity of our results to the empirical method by conducting the regressions on portfolios rather than on individual securities. Second, instead of using VL expected betas, we use realized returns to estimate market betas, and check how sensitive the results are to this change. Third, it is possible that the firm characteristics that we use are proxies for perceived mispricing by VL analysts. Although such a hypothesis is not consistent with the models that we estimate, we attempt to determine whether this interpretation is a viable alternative. Fourth, it is possible that a more accurate proxy for the market's expected return would be to use the prices after the announcement of the target price (and not beforehand, as we have done so far). Using the post-announcement price to calculate the expected return captures market expectations after the new information in the analyst report is announced, and hence better reflects equilibrium expected return. Fifth, to examine whether the results can be attributed to only one particular type of firm, we sort our 
sample firms into terciles based on size, book-to-market, and momentum. We examine the robustness of our earlier regression results within these sorts. ${ }^{19}$

\section{A. Regression Results Based on Portfolio Expected Returns}

We check to see if our results are robust to tests that use characteristics-sorted portfolios of the individual firms. These portfolios are less likely to suffer from noise in the formation of firm expected returns.

The empirical procedure we use is similar that in many of the studies that utilize realized returns. Beginning in June 1970, we form quartile breakpoints based on firms' market beta, tercile breakpoints based on market capitalization, and book-to-market ratio. We base the breakpoints on the universe of firms with available data on the CRSP and Compustat tapes. We use Fama and French's breakpoints for market capitalization and obtain book-to-market from Ken French's web site. We determine the market beta breakpoints by estimating individual firms' betas, using the five years of monthly returns leading to the portfolio formation month.

We then allocate the sample firms into one of the resulting $4 \times 3 \times 3=36$ portfolios and calculate the portfolios' equal-weighted realized return for the next 12 months. We also calculate the average annual expected return, market capitalization, book-to-market, and one-year momentum characteristics. We then re-form these portfolios annually. Next, beginning in January 1975, we estimate the factor loadings for each of the 36 portfolios given Carhart's four-factor model specification using the five-year data preceding this month. We repeat this estimation for all months until December 2001. For each month in the sample period, we use the portfolios' annual expected returns and their estimated factor loadings/characteristics as in Section II. We estimate factor premia using the Fama-MacBeth regression setup.

Table VI provides the regression results. The estimated factor premia are all consistent with those reported in Table III. Market beta is associated with a positive annual premium in both regression specifications. Consistent with our previous results, we find that market capitalization is inversely related to expected returns, and that expected returns are not affected by book-to-market. We also find that the prior-year return is negatively related to our portfolio expected return (We note that the momentum coefficient is not significant in the factor model regression.) Using the portfolio approach, we find that the average $\mathrm{R}^{2}$ is $35 \%$, more than double the $\mathrm{R}^{2}$ when we use individual security returns as the independent variable.

\section{B. Using Historical and Full Sample Market Betas}

Since Value Line reports its estimated market beta, we use it as our market beta rather than estimating it by using historical data. Here, we use two alternative procedures to estimate betas. In the first procedure, we estimate a firm's market beta in a given month t by using the prior 60 months of realized return data. We estimate all other factor loadings (and characteristics) as before. In the second procedure, we estimate, for each firm, full-sample factor loadings by using all available returns data. We then use these sets of estimates in the

\footnotetext{
${ }^{19}$ In unreported analysis, we also examine the robustness of our inferences to potential staleness in the formation of target prices and the inclusion of low priced stocks. To address staleness, that is, the possibility that VL analysts use the previously issued three-month-old target price instead of a fresh target price, we delete from the VL sample all observations in which the analyst's target price is identical to that issued in the previous report. We then repeat the regressions in Table III. We find that the use of this limited sample does not alter any of our conclusions. We also check whether the inclusion of low-priced stocks (price lower than \$5) alters our inferences. We do so by deleting all such cases. Again, our conclusions are unchanged.
} 


\section{Table VI. Fama-MacBeth Portfolio Regressions Based on Value Line Expected Return Estimates, 1975-2001}

This table presents time-series averages of 324 slopes from monthly regressions of portfolio one-year expected excess return on a set of estimated portfolio factor loadings and portfolio characteristics. We form portfolios as follows. Beginning in June 1974 we form quartile breakpoints based on firms' market beta, and tercile breakpoints based on market capitalization and the book-to-market ratio. We base the breakpoints on the universe of firms with data available on the CRSP and Compustat tapes. We allocate sample firms into one of the resulting $4 \times 3 \times 3=36$ portfolios. We calculate the portfolios' equal-weighted realized return for the next 12 months, the average monthly expected return, market capitalization, book-to-market, and one-year momentum characteristics. We then re-form the portfolios annually. Beginning in January 1975, we estimate for each of the 36 portfolios factor loadings given Carhart's four-factor model, using the five-year data that precedes this month. We repeat this estimation monthly until December 2001. We use the portfolios' monthly expected returns and their estimated factor loadings/characteristics as in Table III and estimate the factor premia. Since Value Line provides a firm-specific market beta in each report, we calculate a portfolio's market beta for month $t$ as the equal-weighted average of the firms' Value Line betas for that month. We derive all other factor loadings from a regression over the preceding 60 months. Prior to the portfolio formation, we winsorize individual firm monthly observations at the $1^{\text {st }}$ and $99^{\text {th }}$ percentiles to mitigate the possible effect of extreme observations. The $t$-statistics are adjusted for the overlapping nature of the data. (See Appendix for the details.)

\begin{tabular}{lclc}
\hline \hline \multicolumn{2}{c}{ Factor Loadings } & \multicolumn{2}{c}{ Characteristics } \\
\hline Intercept & 0.056 & Intercept & 0.137 \\
$\beta$ & 2.6 & & 7.2 \\
& 0.060 & & 0.044 \\
$\gamma_{\mathrm{SMB}}$ & 4.8 & $\log ($ Size $)$ & 5.6 \\
& 0.033 & & -0.007 \\
$\gamma_{\mathrm{HML}}$ & 3.2 & $\log ($ Book-to-Market $)$ & -2.2 \\
& 0.004 & Prior Return & 0.005 \\
$\gamma_{\mathrm{PMOM}}$ & 0.4 & & 1.2 \\
& -0.015 & & -0.059 \\
Average Adjusted $\mathrm{R}^{2}$ & -1.8 & Average Adjusted $\mathrm{R}^{2}$ & -4.1 \\
Average Monthly N & $34.7 \%$ & Average Monthly N & $35.0 \%$ \\
\hline \hline
\end{tabular}

Fama MacBeth regressions. Thus, this procedure affects not only market beta, but also size, book-to-market, and momentum loadings.

Panel A, Table VII, reports the results based on historical data. We make special mention of several points. First, the use of historical beta rather than VL beta reduces the estimated market risk premium by almost $50 \%$ (from $6.7 \%$ to $2.9 \%$ ). Second, the use of historical beta significantly increases the intercept. Third, no other slope coefficients are significantly impacted by the alternate estimation procedure for the market beta.

Panel B presents our results based on full-sample factor loadings. Here too we find that estimates of the market premium are lower than those reported in Table III (3.7\% in the fourfactor specification), but the premium associated with firm size is slightly larger than that reported in Table III.

We conclude that our results are robust to the measurement of market beta. However, it is evident that using historical realized return data to estimate market betas seems to introduce measurement error in our second-stage regressions. This error may lead to an error in the variables problem and a lower estimate of the market risk premium. 

Year Expected Excess Return, Using Historical Betas (Panel A) and Full Sample Betas (Panel B), 1975-2001

This table presents the time-series averages of 324 slopes from month-by-month regressions of one-year expected excess returns on a set of estimated factor loadings using historical betas (Panel A) and factor loadings using full sample betas (Panel B). The one-year expected excess return is equal to the difference between the Value Line expected return estimate $\mathrm{ER}^{\mathrm{VL}}$, which was described in Section I.B, and the oneyear risk free rate that we obtain from the Fama-Bliss files on CRSP. We estimate the factor loadings for month $\mathrm{t}$ by using data from months $\mathrm{t}-61$ through $\mathrm{t}-1$. Doing so requires a minimum of 24 valid monthly returns. We compute the size in month $t$ as the log of market capitalization measured as of the end of the previous June (expressed in millions of dollars). We compute book-to-market as the ratio of annual common shareholders equity (Compustat item \#60) to market capitalization as of the end of the fiscal year. We apply the $\log$ of this ratio to the 12-month period beginning six months after the end of the fiscal year. Prior price momentum for month $t$ is the buy-and-hold return for the 11-month period ending one month prior to month $\mathrm{t}$. We winsorize monthly observations at the 1 st and 99 th percentiles to mitigate the possible effect of extreme observations. The $t$-statistics adjusted for the overlapping nature of the data are the ratio of the time-series average divided by the estimated time-series standard error. (See Appendix for the details.)

\begin{tabular}{|c|c|c|c|}
\hline \multicolumn{4}{|c|}{ Panel A. Regressions of One-Year Expected Excess Return on Factor Loadings (using historical betas) } \\
\hline & Model I & Model II & Model III \\
\hline \multirow[t]{2}{*}{ Intercept } & 0.093 & 0.093 & 0.094 \\
\hline & 3.4 & 3.4 & 3.7 \\
\hline \multirow[t]{2}{*}{$\beta_{\text {HISTORICAL }}$} & 0.039 & 0.031 & 0.029 \\
\hline & 4.5 & 4.4 & 4.8 \\
\hline \multirow{2}{*}{$\gamma_{\mathrm{SMB}}$} & & 0.019 & 0.019 \\
\hline & & 2.7 & 2.8 \\
\hline \multirow[t]{2}{*}{$\gamma_{\mathrm{HML}}$} & & -0.007 & -0.007 \\
\hline & & -1.1 & -1.2 \\
\hline \multirow[t]{2}{*}{$\gamma_{\mathrm{PMOM}}$} & & & -0.019 \\
\hline & & & -2.6 \\
\hline Average Adjusted $\mathrm{R}^{2}$ & $5.9 \%$ & $11.7 \%$ & $13.0 \%$ \\
\hline Average Monthly N & 429 & 429 & 429 \\
\hline \multicolumn{4}{|c|}{ Panel B. Regressions of One-Year Expected Excess Return on Factor Loadings (using full sample betas) } \\
\hline & Model I & Model II & Model III \\
\hline \multirow[t]{2}{*}{ Intercept } & 0.078 & 0.076 & 0.080 \\
\hline & 3.1 & 3.8 & 3.6 \\
\hline \multirow[t]{2}{*}{$\beta_{\text {FULL SAMPLE }}$} & 0.054 & 0.046 & 0.041 \\
\hline & 4.6 & 5.0 & 4.2 \\
\hline \multirow[t]{2}{*}{$\gamma_{\mathrm{SMB}}$} & & 0.026 & 0.026 \\
\hline & & 3.4 & 3.1 \\
\hline \multirow[t]{2}{*}{$\gamma_{\mathrm{HML}}$} & & -0.008 & -0.008 \\
\hline & & -1.3 & -1.4 \\
\hline \multirow[t]{2}{*}{$\gamma_{\mathrm{PMOM}}$} & & & -0.023 \\
\hline & & & -1.5 \\
\hline Average Adjusted $\mathrm{R}^{2}$ & $7.6 \%$ & $12.0 \%$ & $13.1 \%$ \\
\hline Average Monthly N & 407 & 407 & 407 \\
\hline
\end{tabular}


We also explore an alternative approach to the estimation of factor loadings that does not rely on the use of realized return data. Following Fama and French (1993), we construct market, size, and book-to-market "factors" using firm expected returns. We then use the 36 portfolios discussed in Section IV.B and estimate the portfolios' factor loadings by regressing each portfolio's time-series of expected returns on the factor expected return series.

We find that first, the three factors explain, on average, $60 \%$ of the time-series variation of the portfolios' expected return over the full sample period. Second, we find that the estimated factor loadings, which are now based exclusively on expected return data, yield results similar to those reported in Panel A of Table III. Third, we find that the portfolio factor loadings that we estimate using ex ante data are highly positively correlated with portfolio factor loadings estimated using realized return data.

\section{The Impact of a Potential Value Line Mispricing Bias}

It is possible that investors are willing to pay for Value Line's advisory services because it is able to identify mispricing in the market. Here, we examine the possibility that the relation between expected return and the models that we documented earlier is actually due to the implicit correlation of these variables with measures of under- and over-valuation. For example, perhaps investors perceive that small firms are more undervalued than large firms. If this were true, it would lead to our estimate of a negative relation between expected return and market capitalization. Although such a robustness test is not consistent with the null equilibrium models that we have used, we believe that it can shed light on the viability of mispricing as a competing hypothesis.

We conduct two separate tests to address this issue. In the first, we use another piece of information provided by VL, the timeliness rank. VL ranks the stocks it follows into five categories, where one is the best rank and five is the worst, based on Value Line prediction of future stock price performance. Unlike sell-side analysts' recommendations, VL recommendations are symmetrically distributed around "timeliness equals three," which is the equivalent of a hold recommendation. ${ }^{20}$

To examine the extent to which our results are affected by potential mispricing, we rerun the factor and characteristic regressions on stocks with a timeliness rank of three. Those stocks (nearly $50 \%$ of the sample) are supposed to be fairly priced. In the second test, we allow for the possibility that on the announcement of the analyst's report, investors immediately react to the hypothesized mispricing component in the forecast. Subsequent to such a reaction, any remaining appreciation between the stock price and the VL target price should reflect the expected return component. Therefore, we recompute all our estimates of expected return as in Equations (1) and (2) by using in the denominator market prices as of five days after the release of the report. We then repeat the analysis in Table III.

Panel A (Panel B) of Table VIII reports the results based on the timeliness rank (post-event price). In general, the results are similar to those we report in Table III when we use the entire sample: 1) The beta slope coefficient is positive and significant for both the factor and characteristic models; 2) the size coefficient indicates that small capitalization stocks are expected to earn higher returns than large cap stocks; 3 ) both the factor and characteristic models suggest that growth stocks (low book-to-market) have an expected return that is not significantly different than value stocks; and 4) both models indicate that past losers can be expected to have higher returns than past winners. Overall, these results clearly suggest

${ }^{20} \mathrm{VL}$ conducts a cross-sectional comparison of every stock in its large 1,700-based company universe. VL assigns 100 firms to group one, 300 into group two, 800 into group three, 300 into group four, and 100 into group five. 


\section{Table VIII. Fama-MacBeth Regressions Based on Value Line Estimates of Expected Return for Observations with a Timeliness Rank 3 and Expected Returns Using Post-Announcement Stock Price, 1975-2001}

This table presents the time-series averages of 324 slopes from month-by-month regressions of one-year expected excess returns on a set of estimated factor loadings and firm characteristics for observations with a timeliness ranking equal to three (Panel A), and regression results using expected returns in which we scale target prices by the stock price outstanding five trading days after the Value Line price forecast announcement (Panel B). Value Line timeliness rank is the rank for a stock's probable relative market performance in the year ahead. The rank ranges from one (highest) to five (lowest). Stocks ranked three (average) might advance or decline with the market in the year ahead. The one-year expected excess return is equal to the difference between the Value Line expected return estimate $\mathrm{ER}^{\mathrm{VL}}$, described in Section I.B, and the one-year risk free rate that we obtain from the Fama-Bliss files on CRSP. We estimate the factor loadings for month t by using data from month $\mathrm{t}-61$ through $\mathrm{t}-1$. Doing so requires a minimum of 24 valid monthly returns. Since Value Line provides a firm-specific market beta in each report, we replace the estimated market beta with the one reported by Value Line. We compute the size in month $\mathrm{t}$ as the $\log$ of market capitalization measured as of the end of the previous June (expressed in millions of dollars). We compute book-to-market as the ratio of annual common shareholders equity (Compustat item \#60) to market capitalization as of the end of the fiscal year. We apply the log of this ratio to the 12-month period beginning six months after the end of the fiscal year. The prior price momentum for month $t$ is the buy-and-hold return for the 11-month period ending one month before month t. We winsorize monthly observations at the $1^{\text {st }}$ and $99^{\text {th }}$ percentiles to mitigate the possible effect of extreme observations. The $t$-statistics adjusted for the overlapping nature of the data are the ratio of the time-series average divided by the estimated time-series standard error. (See Appendix for the details.)

\begin{tabular}{|c|c|c|c|}
\hline \multicolumn{4}{|c|}{ Panel A. Regressions Based on Observations with a Timeliness Rank 3} \\
\hline \multicolumn{2}{|c|}{ Factor Loadings } & \multicolumn{2}{|c|}{ Characteristics } \\
\hline Intercept & $\begin{array}{c}0.058 \\
4.3\end{array}$ & Intercept & $\begin{array}{c}0.115 \\
7.8\end{array}$ \\
\hline$\beta$ & $\begin{array}{c}0.059 \\
5.9\end{array}$ & $\beta$ & $\begin{array}{c}0.068 \\
6.5\end{array}$ \\
\hline$\gamma_{\mathrm{SMB}}$ & $\begin{array}{c}0.015 \\
1.7\end{array}$ & $\log ($ Size $)$ & $\begin{array}{c}-0.007 \\
-2.9\end{array}$ \\
\hline$\gamma_{\mathrm{HML}}$ & $\begin{array}{c}-0.002 \\
-0.5\end{array}$ & $\log ($ Book-to-Market $)$ & $\begin{array}{c}0.005 \\
1.1\end{array}$ \\
\hline$\gamma_{\mathrm{PMOM}}$ & $\begin{array}{c}-0.016 \\
-2.4\end{array}$ & Prior Return & $\begin{array}{l}-0.096 \\
-7.2\end{array}$ \\
\hline Average Adjusted $\mathrm{R}^{2}$ & $14.4 \%$ & Average Adjusted $\mathrm{R}^{2}$ & $22.2 \%$ \\
\hline Average Monthly N & 195 & Average Monthly N & 185 \\
\hline \multicolumn{4}{|c|}{ Panel B. Regressions Based on Post-Announcement Stock Price Expected Returns } \\
\hline \multicolumn{2}{|c|}{ Factor Loadings } & \multicolumn{2}{|c|}{ Characteristics } \\
\hline Intercept & $\begin{array}{c}0.066 \\
4.2\end{array}$ & Intercept & $\begin{array}{c}0.125 \\
5.6\end{array}$ \\
\hline$\beta$ & $\begin{array}{c}0.057 \\
4.5\end{array}$ & $\beta$ & $\begin{array}{c}0.075 \\
6.3\end{array}$ \\
\hline$\gamma_{\mathrm{SMB}}$ & $\begin{array}{c}0.016 \\
2.1\end{array}$ & $\log ($ Size $)$ & $\begin{array}{c}-0.009 \\
-2.5\end{array}$ \\
\hline$\gamma_{\mathrm{HML}}$ & $\begin{array}{c}0.001 \\
0.2\end{array}$ & $\log ($ Book-to-Market $)$ & $\begin{array}{c}0.010 \\
1.8\end{array}$ \\
\hline$\gamma_{\mathrm{PMOM}}$ & $\begin{array}{c}-0.020 \\
-2.8\end{array}$ & Prior Return & $\begin{array}{l}-0.095 \\
-11.2\end{array}$ \\
\hline $\begin{array}{l}\text { Average Adjusted } \mathrm{R}^{2} \\
\text { Average Monthly } \mathrm{N}\end{array}$ & $\begin{array}{c}13.4 \% \\
428\end{array}$ & $\begin{array}{l}\text { Average Adjusted } \mathrm{R}^{2} \\
\text { Average Monthly } \mathrm{N}\end{array}$ & $\begin{array}{c}25.1 \% \\
401\end{array}$ \\
\hline
\end{tabular}


that the relation we find between expected returns and stocks' attributes are not because of perceived mispricing.

\section{Size, Book-to-Market, and Price Momentum Sorts}

We ask if the results reported in the previous section can be attributed to only one particular type of firm. In Table IX, we sort our sample firms into terciles based on size, book-to-market, and momentum, and examine the robustness of our earlier regression results within these sorts. Using tercile breakpoints for each of these three variables, we repeat, each month, the Fama-MacBeth estimation. Panel A of Table IX presents the regression results based on the firm factor loadings. ${ }^{21}$

Beginning with the size sorts, the table shows that within each sort the expected return is positively related to beta, that high book-to-market stocks are not expected to have higher expected returns than low book-to-market stocks, and that recent losers are expected to earn higher returns than recent winners. The sorts by book-to-market and momentum again show that the regression results we report in Table III are not driven by a particular characteristic of the sample firms, because the estimates of the premiums are stable across both kinds of sorts. The market premium is consistently positive and significant, the size premiums are generally positive and significant, the book-to-market coefficients are insignificant, and the price momentum coefficient is negative and significant for all of the sorts. The size (momentum) sort also indicates that the intercept for small (loser) stocks is about double that of large (winner) stocks.

\section{Discussion and Conclusions}

Asset pricing models generate predictions that link assets' expected returns and their attributes. This paper complements and extends existing research by using analysts' expected rates of return and provides evidence on the relation between these expected returns and the pricing of assets in financial markets.

Perhaps the most significant contribution of the article is the evidence that when using expected returns rather than realized returns, beta and expected returns are positively related. Although we find evidence that is not consistent with the CAPM (for example, that firm size is related to expected returns), we believe the fact that beta is associated with an economically significant premium is important, because the model is so widely taught. Further, Graham and Harvey's (2001) survey results show that over $80 \%$ of managers use the CAPM beta to calculate the cost of equity capital. This result is robust to the time period examined. It is also robust regardless of whether we use expected return produced by independent analysts or by sell-side analysts.

We also find that in addition to market beta, the firm's market value of equity is negatively related to its expected return. This finding is consistent with many other studies that utilize average realized return. Combining these two results suggests that the size factor proxies for systematic risk: investors expect small capitalization stocks to generate higher returns. Indeed, realized returns show that on average, small capitalization stocks outperform large capitalization stocks, which is consistent with a risk-return tradeoff.

Several researchers argue that value stocks (high book-to-market stocks) are riskier than growth stocks and therefore, on average, their ex post return is higher. This argument implies that investors should expect such stocks to earn higher returns. Thus, our third important finding is

\footnotetext{
${ }^{21}$ We obtain the breakpoints from Ken French's website: http://mba.tuck.dartmouth.edu/pages/faculty/ken.french/
} 


\section{Table IX. Fama-MacBeth Regressions Within Sorts of Size, Book-to-Market, and} Price Momentum, 1975-2001

This table presents the time-series averages of 324 slopes from month-by-month regressions of one-year expected excess returns on a set of estimated factor loadings (panel A) or firm characteristics (panel B). The calculation of expected excess returns is described in Section I and Table III. We sort firms are each month, into tercile portfolios based on three characteristics: size, book-to-market, and momentum. We obtain breakpoints from http://mba.tuck.dartmouth.edu/pages/faculty/ken.french/. For each portfolio we estimate month-by-month Fama-MacBeth cross-sectional regressions and report the resulting time series averages of the parameter estimates. We estimate the factor loadings used in the regressions for each month $t$ by using data from month $t-61$ through $t-1$. Doing so requires a minimum of 24 valid monthly returns. Since Value Line provides a firm-specific market beta in each report, we replace the estimated market beta with the one reported by Value Line. We winsorize monthly observations at the $1^{\text {st }}$ and $99^{\text {th }}$ percentiles to mitigate the possible effect of extreme observations. The $t$-statistics adjusted for the overlapping nature of the data are the ratio of the time-series average divided by the estimated time-series standard error. (See Appendix for the details.)

\begin{tabular}{|c|c|c|c|c|c|c|c|c|c|}
\hline \multicolumn{10}{|c|}{ Panel A. Regressions of Value Line One-Year Expected Excess Return on Factor Loadings } \\
\hline & \multicolumn{3}{|c|}{ Size } & \multicolumn{3}{|c|}{ Book-to-Market } & \multirow{2}{*}{\multicolumn{3}{|c|}{$\begin{array}{c}\text { Price Momentum } \\
\text { Loser Medium Winner }\end{array}$}} \\
\hline & Small & Medium & Large & Low & Medium & High & & & \\
\hline \multirow[t]{2}{*}{ Intercept } & 0.090 & 0.055 & 0.038 & 0.073 & 0.053 & 0.098 & 0.106 & 0.060 & 0.059 \\
\hline & 3.9 & 3.3 & 2.8 & 4.3 & 4.4 & 4.2 & 8.0 & 5.2 & 3.2 \\
\hline \multirow[t]{2}{*}{$\beta$} & 0.073 & 0.073 & 0.073 & 0.046 & 0.072 & 0.053 & 0.060 & 0.063 & 0.036 \\
\hline & 7.0 & 6.7 & 3.5 & 3.2 & 5.4 & 4.5 & 4.2 & 4.4 & 5.5 \\
\hline \multirow[t]{2}{*}{$\gamma_{\mathrm{SMB}}$} & 0.005 & 0.004 & -0.002 & 0.012 & 0.015 & 0.009 & 0.015 & 0.017 & 0.010 \\
\hline & 1.2 & 0.7 & -0.2 & 1.5 & 2.2 & 1.4 & 4.9 & 2.7 & 2.2 \\
\hline \multirow[t]{2}{*}{$\gamma_{\mathrm{HML}}$} & -0.002 & 0.001 & 0.005 & -0.002 & -0.001 & -0.006 & -0.002 & 0.002 & 0.004 \\
\hline & -0.8 & 0.1 & 0.8 & -0.4 & -0.2 & -1.7 & -0.5 & 0.7 & 1.5 \\
\hline \multirow[t]{2}{*}{$\gamma_{\text {PMOM }}$} & -0.012 & -0.016 & -0.024 & -0.018 & -0.020 & -0.014 & -0.014 & -0.017 & -0.017 \\
\hline & -4.7 & -2.5 & -2.7 & -2.6 & -3.3 & -3.3 & -4.8 & -3.8 & -4.6 \\
\hline Average Adjusted $\mathrm{R}^{2}$ & $8.5 \%$ & $13.9 \%$ & $15.0 \%$ & $13.0 \%$ & $15.9 \%$ & $9.4 \%$ & $10.7 \%$ & $15.3 \%$ & $9.0 \%$ \\
\hline Average Monthly N & 102 & 183 & 142 & 155 & 179 & 80 & 123 & 173 & 131 \\
\hline \multicolumn{10}{|c|}{ Panel B. Regressions of Value Line One-Year Expected Excess Return on Firm Characteristics } \\
\hline & \multicolumn{3}{|c|}{ Size } & \multicolumn{3}{|c|}{ Book-to-Market } & \multicolumn{3}{|c|}{ Price Momentum } \\
\hline & Small & Medium & Large & Low & Medium & High & Loser & Medium & Winner \\
\hline \multirow{2}{*}{ Intercept } & 0.109 & 0.075 & 0.060 & 0.139 & 0.112 & 0.127 & 0.119 & 0.114 & 0.117 \\
\hline & 5.0 & 6. & 3.0 & 5.5 & 7.4 & 5.8 & 5.2 & & 5.3 \\
\hline \multirow[t]{2}{*}{$\beta$} & 0.073 & 0.078 & 0.079 & 0.060 & 0.087 & 0.071 & 0.063 & 0.080 & 0.059 \\
\hline & 6.6 & 7.1 & 4.0 & 5.7 & 5.2 & 6.4 & 5.4 & 5.5 & 8.5 \\
\hline \multirow[t]{2}{*}{$\log ($ Size $)$} & -0.002 & -0.001 & -0.001 & -0.009 & -0.009 & -0.006 & -0.005 & -0.008 & -0.008 \\
\hline & -0.4 & -0.9 & -0.3 & -2.0 & -3.5 & -2.2 & -2.5 & -2.8 & -3.0 \\
\hline \multirow[t]{2}{*}{$\log$ (Book-to-Market) } & 0.006 & 0.010 & 0.013 & 0.004 & 0.014 & 0.008 & 0.010 & 0.011 & 0.013 \\
\hline & 1.6 & 1.8 & 2.1 & 1.1 & 1.2 & 1.5 & 1.9 & 2.1 & 2.7 \\
\hline \multirow[t]{2}{*}{ Prior Return } & -0.093 & -0.093 & -0.094 & -0.098 & -0.097 & -0.095 & -0.147 & -0.120 & -0.047 \\
\hline & -12.7 & -11.1 & -11.3 & -12.0 & -12.3 & -13.6 & -17.9 & -10.8 & -7.3 \\
\hline Average Adjusted $\mathrm{R}^{2}$ & $17.7 \%$ & $23.9 \%$ & $24.4 \%$ & $25.4 \%$ & $26.2 \%$ & $19.5 \%$ & $15.4 \%$ & $17.8 \%$ & $12.7 \%$ \\
\hline Average Monthly N & 93 & 174 & 133 & 149 & 178 & 74 & 114 & 165 & 122 \\
\hline
\end{tabular}


that there is little evidence in favor of the hypothesis that book-to-market is a risk factor. We are unable to find reliable evidence that investors expect high book-to-market stocks to generate higher returns than low book-to-market stocks.

Although market expectations are unobservable, as we point out in the introduction, all of our major findings can be corroborated by using an additional set of expectations, those of sell-side analysts. There are several reasons to believe the expectations we use here represent at least a significant portion of the market's expectations. Both sources of expectations are followed by a wide number of investors, and it is common practice to use analysts' earnings forecasts for companies' valuation, which directly affect prices. In addition, the results in Vissing-Jorgenson (2003) indicate that the First Call analysts' expectations are correlated with that of individual investors.

As long as the set of expectations we use are correlated with the market's expectations, our results are informative about the relation between the market's expected returns and asset pricing. Given the literature's ubiquitous reliance on realized returns in tests of assets pricing models over the past three decades, our results should provide a valuable alternative source of evidence on the viability of the asset pricing models that we frequently use.

\section{Appendix. Computation of Adjusted $t$-Statistics}

Here, we describe the manner in which we derive the standard errors for the estimates reported in the tables. To begin, we consider the Fama-MacBeth regression in which the null asset-pricing model is the CAPM. The regression for each period takes the form:

$$
E R-R_{f}=\gamma_{0}+\gamma_{1} \beta+v
$$

Without loss of generality, we focus on the vector of time series of estimated slopes $\hat{\gamma}_{1, t}$, and drop the subscript for convenience. We note that $t=1, \ldots, 60$ in the case of First Call based estimates of expected return and $t=1, \ldots, 180$ in the case of Value Line. Our goal is to derive the standard error for the time-series average,

$$
\frac{1}{T} \sum_{t=1}^{T} \gamma_{t} .
$$

We begin with the estimation of a $\mathrm{p}^{\text {th }}$-order autoregression for the demeaned vector $\hat{\gamma}$.

$$
\hat{\gamma}_{t}=\rho_{1} \hat{\gamma}_{t-1}+\rho_{2} \hat{\gamma}_{t-2}+\ldots \rho_{p} \hat{\gamma}_{t-p}+\varepsilon_{t}
$$

For the First-Call based regressions we adopt an AR(3) specification. For the Value-Line based regressions we specify an AR(6). For both databases, we have verified that higher orders of the autoregression process do not lead to any changes in the reported inferences.

To ease the derivation, we convert the p-order autoregression in (A2) into a first-order vector autoregression. We denote the $(1 \mathrm{xp})$ vector of estimated autoregressive parameters by $\hat{\rho}$ and let:

$$
y_{t}=A y_{t-1}+\eta_{t},
$$


where

$y_{t}=\left[\hat{\gamma}_{t} \hat{\gamma}_{t-1} \ldots \hat{\gamma}_{t-p+1}\right]^{\prime}$

is a (px1) vector of estimated slopes,

$A=\left[\begin{array}{ll}\hat{\rho} & \\ I_{p-1} & 0\end{array}\right]$

is a ( $\mathrm{p} \mathrm{x} \mathrm{p)} \mathrm{matrix} \mathrm{and} \mathrm{I}_{\mathrm{p}-1}$ is a $(\mathrm{p}-1 \mathrm{x} \mathrm{p}-1)$ identity matrix. The disturbance term $\eta_{t}=\left[\varepsilon_{t} \underline{0}\right]$ is a ( $\mathrm{p} \times 1)$ vector with the scalar $\varepsilon_{\mathrm{t}}$ in the $(1,1)$ position, and zero is a $(\mathrm{p}-1 \times 1)$ vector of zeros. We assume that $\eta_{t} \sim \operatorname{IID} N(0, \Sigma)$, where $\Sigma$ is a (p x p) matrix with the scalar $\sigma_{\varepsilon}^{2}$, namely, the residual variance from $(\mathrm{A} 2)$, in the $(1,1)$ position, and zeros otherwise. We can express the covariance matrix of the sample average

$$
\begin{aligned}
& \frac{1}{T} \sum_{t=1}^{T} y_{t} \text { as: } \\
& \operatorname{VAR}\left(\frac{1}{T} \sum_{t=1}^{T} y_{t}\right)=\frac{1}{T} \cdot\left[I_{p_{2}}-A \otimes A\right]^{-1} \operatorname{vec}(\Sigma) \cdot\left(I_{p}+\sum_{i=1}^{T-1}\left(\frac{T-i}{T}\right) \cdot\left(A^{i}+\left(A^{\prime}\right)^{i}\right)\right)
\end{aligned}
$$

(See Hamilton, 1994, p. 265, for a formal derivation of the second moment for a vector autoregression process). The square root of the $(1,1)$ element of the covariance matrix is the standard error we are interested in. 


\section{References}

Affleck-Graves, J. and R. Mendenhall, 1992, "The Relation between the Value Line Enigma and the Post Earnings-Announcement Drift," Journal of Financial Economics 31, 75-96.

Ang, J.A. and D.R. Peterson, 1985, "Return, Risk, and Yield: Evidence from Ex Ante Data," Journal of Finance 40, 537-548.

Banz, R.W., 1981, “The Relationship between Return and Market Value of Common Stocks," Journal of Financial Economics 9, 3-18.

Barber, B., R. Lehavy, and B. Trueman, 2005, "Comparing the Stock Recommendations Performance of Investment Banks and Independent Research Firms," Working Paper.

Barber, B., R. Lehavy, M. McNichols, and B. Trueman, 2001, “Can Investors Profit from the Prophets? Security Analyst Recommendations and Stock Returns,” Journal of Finance 56, 531-565.

Black, F., 1972, “Capital Market Equilibrium with Restricted Borrowing,” Journal of Business 45, 444-455.

Black, F., 1986, “Noise,” Journal of Finance 41, 529-43.

Black, F., M. Jensen, and M. Scholes, 1972, “The Capital Asset Pricing Model: Some Empirical Tests," Studies in the Theory of Capital Markets, M. Jensen, Ed., New York, NY, Praeger.

Bloomfield, R. and R. Michaely, 2004, "Risk or Mispricing? From the Mouths of Professionals," Financial Management 33, 61-81.

Blume, L.E. and D. Easley, 1982, "Learning to be Rational,” Journal of Economic Theory 26, 340-351.

Blume, L.E. and D. Easley, 1998, "Rational Expectations and Rational Learning," Organizations with Incomplete Information: Essays in Economic Analysis: A Tribute to Roy Radner, Majumdar, Mukul, Ed., Cambridge, New York and Melbourne, Cambridge University Press, 61-109.

Blume, M.E. and I. Friend, 1973, “A New Look at the Capital Asset Pricing Model,” Journal of Finance 28, $19-33$.

Botosan, C.A. and M.A. Plumlee, 2005, “Assessing Alternative Proxies for the Expected Risk Premium,' Accounting Review 80, 21-54.

Brav, A. and J.B. Heaton, 2002, "Competing Theories of Financial Anomalies," Review of Financial Studies 15, 475-506.

Brav, A. and R. Lehavy, 2003, “An Empirical Analysis of Analysts' Target Prices: Short-term Informativeness and Long-Term Dynamics,” Journal of Finance, 1933-1967.

Bray, M.M. and D.M. Kreps, 1987, "Rational Learning and Rational Expectations." Arrow and the Ascent of Modern Economic Theory, G.R. Feiwel, Ed., New York, NY, New York University Press.

Carhart, M., 1997, “On Persistence in Mutual Fund Performance,” Journal of Finance 52, 57-82.

Claus, J. and J. Thomas, 2001, “The Equity Risk Premium is Much Lower than You Think It Is: Empirical Estimates from a New Approach,” Journal of Finance 56, 1629-1666.

Davis, J., E. Fama, and K. French, 2000, “Characteristics, Covariances, and Average Returns: 1929-1997," Journal of Finance, 55, 389-406.

De Bondt, W.F.M. and R.H. Thaler, 1985, “Does the Stock Market Overreact?” Journal of Finance 40, 793-807.

De Bondt, W.F.M. and R.H. Thaler, 1987, "Further Evidence of Investor Overreaction," The Journal of Finance 42, 557-581.

Elton, E.J., 1999, “Expected Return, Realized Return, and Asset Pricing Tests,” Journal of Finance 54, 1199-1220. 
Fama, E.F. and J. MacBeth, 1973, "Risk, Return, and Equilibrium: Empirical Tests," Journal of Political Economy 81, 607-636.

Fama, E.F. and K.R. French, 1992, "The Cross-Section of Expected Stock Returns," Journal of Finance 47, $427-465$.

Fama, E.F. and K.R. French, 1993, "Common Risk Factors in the Returns on Stocks and Bonds," Journal of Financial Economics 33, 3-56.

Fama, E.F. and K.R. French, 2001, “The Equity Premium,” Journal of Finance 57, 637-659.

Friedman, M., 1953, "The Methodology of Positive Economics," in Essays in Positive Economics, The University of Chicago Press.

Friend, I., R. Westerfield, and M. Granito, 1978, "New Evidence on the Capital Asset Pricing Model," Papers and Proceedings of the Thirty-Sixth Annual Meeting American Finance Association, Journal of Finance 33, 903-917.

Froot, K., 1989, "New Hope for the Expectations Hypothesis of the Term Structure of Iinterest Rates," Journal of Finance 44, 283-305.

Froot, K. and J.A. Frankel, 1989, "Forward Discount Bias: Is it an Exchange Risk Premium?" Quarterly Journal of Economics 104, 139-161.

Gebhardt, W., C.M.C. Lee, and B. Swaminathan, 2001, “Toward an Implied Cost-of-Capital,” Journal of Accounting Research 39, 135-176.

Graham, J. and C. Harvey, 2001, “The Theory and Practice of Corporate Finance: Evidence from the Field," Journal of Financial Economics 60, 187-243.

Hamilton, J.D., 1994, Time Series Analysis, Princeton, NJ, Princeton University Press.

Harris, R., F. Marston, D. Mishra, and T. O'Brien, 2003, "Ex Ante Cost of Equity Estimates of S\&P 500 Firms and Global vs Domestic CAPM,” Financial Management 32, 51-66.

Huberman, G. and S. Kandel, 1990, "Market Efficiency and Value Line's Record,” Journal of Business 63, $187-216$

Jagannathan, R. and Z. Wang, 1996, "The Conditional CAPM and Cross-Section of Expected Returns," Journal of Finance 51, 3-53.

Jagannathan, R., E.R. McGrattan, and A. Scherbina, 2000, “The Declining US Equity Premium," Quarterly Review 24, 3-19.

Jegadeesh, N. and S. Titman, 1993, "Returns for Buying Winners and Selling Losers: Implications for Stock Market Efficiency," Journal of Finance 48, 65-91.

Jegadeesh, N., J. Kim, S.D. Krische, and C.M.C. Lee, 2004, "Analyzing the Analysts: When Do Recommendations Add Value?” Journal of Finance 59, 1083-1125.

Kothari, S.P., J. Shanken, and R. Sloan, 1995, "Another Look at the Cross Section of Expected Stock Returns," Journal of Finance 50, 185-224.

Lewellen, J. and J. Shanken, 2002, "Learning, Asset Pricing Tests, and Market Efficiency," Journal of Finance 57, 1113-1146.

Lintner, J., 1965, "The Valuation of Risk Assets and the Selection of Risky Investments in Stock Portfolios and Capital Budgets," Review of Economics and Statistics 47, 13-37.

Merton, R.C., 1973, “An Intertemporal Capital Asset Pricing Model,” Econometrica 41, 867-887.

Michaely, R. and K.L. Womack, 1999, "Conflict of Interest and the Credibility of Underwriter Analyst Recommendations," Review of Financial Studies 12, 653-86. 
Pontiff, J., 1996, “Costly Arbitrage: Evidence from Closed End Funds," Quarterly Journal of Economics $111,1135-1151$.

Rajan, R. and H. Servaes, 1997, “Analyst Following of Initial Public Offerings,” Journal of Finance 52, 507-529.

Reinganum, M., 1981, "Misspecification of Capital AssetPricing: Empirical Anomalies based on Earnings Yield and Market Value," Journal of Financial Economics 9, 19-46.

Reisman, H., 1992, "Reference Variables, Factor Structure, and the Multibeta Representation," Journal of Finance 47, 1303-1314.

Reisman, H., 2001, “The APT with Accounting Variables instead of Betas,” Technion, Israel Institute of Technology Working paper.

Rouwenhorst, G., 1998, “International Momentum Strategies,” Journal of Finance 53, 267-284.

Sharpe, W.F., 1964, "Capital Asset Prices: A Theory of Market Equilibrium under Conditions of Risk," Journal of Finance 19, 425-442.

Sharpe, W.F., 1978, "New Evidence on the Capital Asset Pricing Model: Discussion,” Journal of Finance 33, 917-920.

Shefrin, H. and M. Statman, 2002, "The Style of Investor Expectations," The Handbook of Equity Style Management, Thomas Coggin and Frank Fabozzi, Ed. (Forthcoming).

Stickel, S., 2001, "The Financial Characteristics of and Returns to Wall Street Darlings and Dogs," Working Paper.

Womack, K.L., 1996, “Do Brokerage Analysts’ Recommendations have Investment Value?” Journal of Finance 51, 137-167.

Welch, I., 2000, "Views of Financial Economists on the Equity Premium and on Professional Controversies," Journal of Business 73, 501-537.

Value Line Methods of Evaluating Common Stocks Building and Maintaining Portfolio, 1979, New York, NY, Arnold Bernhard \& Co., Inc..

Vissing-Jorgensen, A., 2003, "Perspectives on Behavioral Finance: Does "Irrationality" Disappear with Wealth? Evidence from Expectations and Actions," NBER Macroeconomics Annual. 